\title{
Subsequent monitoring of ferric ion and ascorbic acid using graphdiyne quantum dots-based optical sensors
}

Qiang Bai ${ }^{\mathrm{a}, \mathrm{c}}$, Chaoyang Zhang ${ }^{\mathrm{b}}$, Long $\mathrm{Li}^{\mathrm{b}}$, Zhiling Zhu', Lina Wang ${ }^{\mathrm{b}, *}$, Fuyi Jiang ${ }^{\mathrm{c}}$, Manhong Liu ${ }^{\mathrm{a}}$, Zhaobo Wang ${ }^{\mathrm{a}}$, William W. Yu ${ }^{\mathrm{a}, \mathrm{d}}$, Fanglin Du ${ }^{\mathrm{a}, *}$, Zhugen Yang ${ }^{\mathrm{e}, *}$, Ning $\mathrm{Sui}^{\mathrm{a}, *}$

${ }^{\text {a }}$ College of Materials Science and Engineering, Qingdao University of Science and Technology, Qingdao 266042, China

${ }^{\mathrm{b}}$ College of Environment and Safety Engineering, Qingdao University of Science and Technology, Qingdao, 266042, China.

${ }^{c}$ School of Environment and Material Engineering, Yantai University, Yantai, 264005, Shandong, China

${ }^{\mathrm{d}}$ Department of Chemistry and Physics, Louisiana State University Shreveport, LA 71115, USA

${ }^{\mathrm{e}}$ Cranfield Water Science Institute, Cranfield University, Milton Keynes, MK43 OAL, United Kingdom

* Corresponding authors: suining@qust.edu.cn (N. Sui), lnwang2006@163.com (L.N. Wang), dufanglin@qust.edu.cn (F.L. Du), zhugen.yang@cranfield.ac.uk (Z.G. Yang) 


\begin{abstract}
Graphdiyne (GDY) as an emerging carbon nanomaterial has attracted increasing attention because of its uniformly distributed pores, highly $\pi$-conjugated, and tunable electronic properties. These excellent characteristics have been widely explored in the fields of energy storage, catalysts, there is yet report on the sensors development based on its outstanding optical property. In this paper, we report on a new sensing mechanism built upon the synergistic effect between inner filter effect and photoinduced electron transfer. We constructed a novel nanosensor based upon the newly-synthesized nanomaterial and demonstrated a sensitive and selective detection for both ion $\left(\mathrm{Fe}^{3+}\right)$ and ascorbic acid, enabling the measurements in real clinical samples. We firstly prepared fluorescent graphdiyne oxide quantum dots (GDYO-QDs) with a facile ultrasonic protocol and characterized them with a range of techniques, showing a strong blue-green emission with $14.6 \%$ quantum yield. And it can be quenched efficiently by $\mathrm{Fe}^{3+}$ and recovered by ascorbic acid (AA). We have fabricated a Off/On fluorescent nanosensors based on the unique property. Our nanosensors are able to detect $\mathrm{Fe}^{3+}$ as

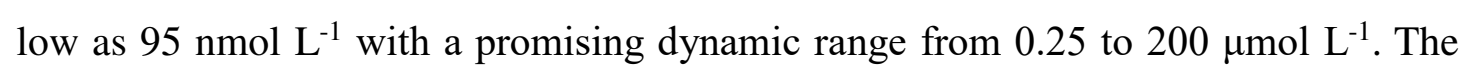
LOD of AA was $2.5 \mu \mathrm{mol} \mathrm{L} \mathrm{L}^{-1}$, with range of $10-500 \mu \mathrm{mol} \mathrm{L}{ }^{-1}$. It showed a promising capability to detect $\mathrm{Fe}^{3+}$ and $\mathrm{AA}$ in serum samples compared to refereed technique.
\end{abstract}

Key words: fluorescence, quenching, graphdiyne, quantum dots, $\mathrm{Fe}^{3+}$, ascorbic acid 


\section{Introduction}

As one of the most trace metal elements in human bodies, iron $(\mathrm{Fe})$ is the core part of hemoglobin and plays an important role in transporting oxygen and participating in human metabolism. [1-5] However, abnormal $\mathrm{Fe}^{3+}$ fluctuation is hazardous to human bodies, which can cause diseases, such as anemia, hepatitis, intelligence decline, agitans paralysis, and cancer. [6-8] Therefore, the monitoring of $\mathrm{Fe}^{3+}$ content is always an active issue in biosensing. Plenty of methods can be used to detect the above substances, such as mass spectroscopy [9], electrochemistry [10], colorimetric analysis [11, 12], amperometry [13] and florescence spectroscopy analysis [14-16]. Among them, fluorescence spectroscopy is a favorite method because of its simplicity, rapid response, and high sensitivity. [17, 18] Therefore, plenty of fluorescent sensors have been developed for $\mathrm{Fe}^{3+}$ detection. [19-21]

Quantum dots (QDs) are important materials in fluorescent sensors, due to their high stability, easy surface bioconjugation, and adaptable photophysical properties. [22] Traditional semiconductor QDs, including $\mathrm{CdSe}, \mathrm{PbS}, \mathrm{CdS}$, are toxic for bioassay especially for in vivo applications due to the risk of leakage of heavy metal elements. $[23,24]$ Carbon-based QDs have inspired extensive interest because of their excellent optical property, low toxicity, chemical inertia and good biocompatibility. [25, 26] The representative carbon-based QDs, graphene QDs (GQDs) and carbon dots (CDs), have been widely used in fluorescent sensors for metal ions (such as $\mathrm{Fe}^{3+}, \mathrm{Cu}^{2+}, \mathrm{Hg}^{2+}$ ), [21, $27,28]$ the detection is influenced by the aspects of internal structure, surface state, and doping elements. [29] For $\mathrm{Fe}^{3+}$ detection, the effective strategy is $\mathrm{N}$ or $\mathrm{S}$ doping, [30, 31] which complicate the preparation of carbon-based QDs. Furthermore, the doping of heteroatoms such as $\mathrm{N}$ and $\mathrm{S}$ will increase the affinity of carbon-based QDs sensors to many other metal ions, which leading the low selectivity. The development of new type of carbon-based QDs without doping $\mathrm{N}$ or $\mathrm{S}$ may improve the selectivity.

Graphdiyne (GDY) is a new two-dimensional carbon nanomaterial comprising $\mathrm{sp}^{2}$ and sp-hybridized carbon atoms with high $\pi$-conjugation. It has large triangular rings composed of 18 carbon atoms, which forms uniformly distributed pores. [32] All of 
these special characteristics makes it unique electronic, optical, and electrochemical properties, which have been utilized as sensor materials. [33, 34] Due to its large $\pi$ conjugated surface, Li's group first reported GDY nanosheets as fluorescence quencher for DNA detection. [33] Wang's group also successfully applied GDY nanosheets for real-time fluorescence detection of DNA based on similar principle. [35] Wang developed a GDY based photoelectrochemical sensor, in which graphdiyne oxide nanosheets worked as signal inhibitor due to their unique electronic structure. [34] To the best of our knowledge, no sensor has been reported based on the optical property of GDY itself.

GDY is a semiconductor and its band gap can be tuned in the range of $0.14-1.22 \mathrm{eV}$ based on the manner of stacking and number of layers. [36] GDY processes an outstanding extinction coefficient in the near-infrared region, thus it was used as photothermal conversion agents and imaging for tumor diagnosis and therapy. [37] It is known that the fluorescence of semiconductor can be tuned by changing its size, especially when the size is smaller than or equal to $10 \mathrm{~nm}$, i.e. quantum dots (QDs). [38] The synthesis and study the fluorescent property of GDY based QDs may supplement available carbon based fluorescent materials, yet only one work reported graphdiyne oxide quantum dots (GDYO-QDs), they were used for bio-imaging. [39] The presence of triple bonds and large triangular rings facilitate the coordination with metal ions. [11] This may change the surface state or electronic structure of GDYO-QDs, leading the variation of their fluorescent property.

Based on the above assumption, we here report the synthesis GDYO-QDs using ultrasonic method firstly. Their fluorescence was quenched by the addition of $\mathrm{Fe}^{3+}$, and the fluorescence was recovered by AA due to the reduction of $\mathrm{Fe}^{3+}$ to $\mathrm{Fe}^{2+}$. Thus, an off/on sensor for $\mathrm{Fe}^{3+}$ and AA detection was established, as illustrated in Fig. 1. The detection condition optimization, sensitivity, and selectivity were investigated. The mechanism was proposed. Finally, GDYO-QDs were successfully applied to the quantitative determination of $\mathrm{Fe}^{3+}$ and $\mathrm{AA}$ in human serum. Our work provides a new carbon based QDs as optical sensor for $\mathrm{Fe}^{3+}$ and AA detection, it exhibited an excellent analytical performance. 


\section{Experimental Section}

2.1. Materials and Methods.

Ascorbic acid, $\mathrm{Fe}\left(\mathrm{NO}_{3}\right)_{3}, \mathrm{MnCl}_{2}, \mathrm{CaCl}_{2}, \mathrm{Ni}\left(\mathrm{NO}_{3}\right)_{2}, \mathrm{NaCl}, \mathrm{CuCl} 2, \mathrm{Zn}\left(\mathrm{NO}_{3}\right)_{2}, \mathrm{CdCl}_{2}$, $\mathrm{PbCl}_{2}, \mathrm{NaOH}, \mathrm{HCl}$ and Phosphoric acid were purchased from Sinopharmaceutical Group Chemical Reagent Co., Ltd. THF and TBAF were purchased from Aladin Ltd. All reagents and solvents were purchased without further purification. Ultrapure water was used in the whole experiment. Fluorescent emission (FL) spectra were recorded on a Hitachi F-4600 luminescence spectrometer (Hitachi High-Tech Co., Ltd.). Fourier transform infrared (FT-IR) spectra $\left(4000-400 \mathrm{~cm}^{-1}\right)$ were recorded on a Magna-560 spectrometer (Nicolet, Madison, WI). The transmission electron microscope (TEM) images were obtained from a JEOL-2010F microscope (Japan). The atomic force microscope (AFM) was performed using mica as the analytical substrate by Auto-probe CP Research (Thermo company, US). UV-vis spectra were collected on a TU-1900 spectrophotometer. X-ray photoelectron spectroscopy (XPS) was measured on a Thermo ESCALAB VG Science 250 spectrometer with monochromatic Al Ka excitation. The Raman spectra were analyzed by T64000 of HORIBA Scientific Company.

\subsection{Materials Synthesis.}

Firstly, the copper sheet is washed with $\mathrm{HCl}(4 \mathrm{M})$ and washed with water and ethanol under ultrasound. The copper sheet and pyridine $(60 \mathrm{~mL})$ were put into a three-port flask and heated at $120^{\circ} \mathrm{C}$ for $1 \mathrm{~h}$ under the protection of $\mathrm{N}_{2}$. Under the condition of ice bath, hexaethynylbenzene $(200 \mathrm{mg})$ was dissolved in tetrahydrofuran (THF) of $50 \mathrm{~mL}$, and 30 minutes was purged with nitrogen. $1 \mathrm{M}$ TBAF was added to tetrahydrofuran $(2.5$ $\mathrm{mL}$ ) and stirred at low temperature in nitrogen for 15 minutes. The reaction mixture was diluted with ethyl acetate, washed with saturated $\mathrm{NaCl}$ for 3 times, dried and filtered. The dried hexaethynylbenzene precursor was dissolved in pyridine $(50 \mathrm{~mL})$, transferred to a constant addition funnel protected by $\mathrm{N}_{2}$, and dripped into the mixture containing pyridine $(60 \mathrm{~mL})$ and copper sheet at $80{ }^{\circ} \mathrm{C}$. The addition process lasted for 
10 hours. After adding the deprotected compound, the reaction mixture was kept at $120{ }^{\circ} \mathrm{C}$ for 3 days. After the reaction is completed, it is freeze-dried to evaporate pyridine. The crust products were collected by centrifugation, washed successively with hot DMF $\left(80^{\circ} \mathrm{C}\right)$ and ethanol $\left(70^{\circ} \mathrm{C}\right)$, and dried to obtain GDY. [32] Graphdiyne oxide (GDYO) was synthesized by acid-oxidation treatment. Briefly, GDY powder (10 mg) was first mixed with concentrated $\mathrm{H}_{2} \mathrm{SO}_{4}(98 \%, 2.5 \mathrm{~mL})$ and hydrogen peroxide (30\%, $1.0 \mathrm{~mL}$ ). Then, the mixture was stirred in an ice-water bath for 1 hour. After centrifugation (8000 rpm, $10 \mathrm{~min}$ ) and washing with ultra-pure water, the obtained suspension was freeze-dried to obtain GDYO.[40] GDYO-QDs were obtained by treating GDYO aqueous suspension $(10 \mathrm{~mL}, 0.5 \mathrm{mg} / \mathrm{mL})$ with ultrasonic $(120 \mathrm{~W}, 30$ $\mathrm{kHz})$ for 24 hours. The obtained solution was heated by oil bath $\left(100{ }^{\circ} \mathrm{C}, 6 \mathrm{~h}\right)$, then centrifuged to get the supernatant, and GDYO-QDs were obtained.

\subsection{Determination of $\mathrm{Fe}^{3+}$ and AA.}

The fluorescence quenching of GDYO-QDs was carried out by $\mathrm{Fe}^{3+}$ at room temperature. In a typical operation, $200 \mu \mathrm{L}$ of GDYO-QD $\left(0.1 \mathrm{mg} \mathrm{mL}^{-1}\right)$ solution was added to a Britton-Robinson $(\mathrm{B}-\mathrm{R})$ buffer solution $\left(0.1 \mathrm{~mol} \mathrm{~L}^{-1}, \mathrm{pH}=6.0\right)$. Different concentrations of $\mathrm{Fe}^{3+}$ solution and other metal ion solutions were freshly prepared before use. And the final volume of the mixture was $2.0 \mathrm{~mL}$. For $\mathrm{Fe}^{3+}$ detection, different concentration of $\mathrm{Fe}^{3+}$ was added to the $\mathrm{B}-\mathrm{R}$ buffer containing the same amount of GDYO-QDs, and the mixed solution was standing at room temperature for 20 minutes before spectral measurement. For AA detection, $200 \mu \mathrm{L}$ GDYO-QDs $(0.1 \mathrm{mg}$ $\left.\mathrm{mL}^{-1}\right)$ and $200 \mu \mathrm{L}$ of $\mathrm{Fe}^{3+}\left(2 \mathrm{mmol} \mathrm{L}{ }^{-1}\right)$ were added the $\mathrm{B}-\mathrm{R}$ buffer $\left(0.1 \mathrm{~mol} \mathrm{~L}^{-1}, \mathrm{pH}=\right.$ 6.0). Consequently, different concentrations of AA solutions were added to the above mixture. The final volume of above mixture was $2.0 \mathrm{~mL}$. The FL spectrum was recorded by fluorescence spectrophotometer at room temperature, and the excitation wavelength was $331 \mathrm{~nm}$.

2.4. Detection of $\mathrm{Fe}^{3+}$ and $\mathrm{AA}$ in real sample.

Briefly, the treatment of human serum samples each serum sample was transferred to a cylindrical centrifuge tube, adding the same amount of ultra-pure water for swirling 
mixing, and centrifuged 10 minutes at the speed of $6000 \mathrm{rpm}$. Then, remove the aluminum cover and transfer the clarified supernatant to the glass bottle for use in the next test. In order to determine $\mathrm{Fe}^{3+}$ in serum samples, the treated human serum was added to GDYO-QDs solution. In addition, Serum sample 1 was further added with $\mathrm{Fe}^{3+}$ concentration of $50,100,150 \mu \mathrm{mol} \mathrm{L}{ }^{-1}$, respectively. It was used to explore the recovery rates. The serum sample detection of $\mathrm{Fe}^{3+}$ was done with adding GDYO-QDs and $\mathrm{Fe}^{3+}$ after placing it for 20 minutes. At the same time, we also applied the sensor to the analysis of AA in human serum. Human serum samples were added to GDYOQDs/ $\mathrm{Fe}^{3+}\left(200 \mu \mathrm{mol} \mathrm{L}{ }^{-1}\right)$ solution. Then mixed with different concentrations of AA (50, 200, $\left.400 \mu \mathrm{mol} \mathrm{L}{ }^{-1}\right)$. The serum sample detection of AA was done with adding GDYOQDs after placing it for 3 minutes. All the above tests were tested at room temperature.

\section{Results and discussion}

\subsection{Characterization of GDY and GDYO-QDs.}

< Fig. 2.>

In this work, GDY was prepared by cross-coupling reaction of hexaethynylbenzene precursor on copper surface, and GDY powder was oxidized by the strong oxidation. GDYO-QDs was further prepared by physical ultrasonic crushing. The morphologies of the as-prepared GDYO-QDs were characterized by TEM, as shown in Fig. 2a. Their diameters were $4.45 \pm 2 \mathrm{~nm}$ (by judging from image analyses of 100 individual particles). Fig. 2b shows the HRTEM images of GDYO-QDs, they clearly reveal a good crystallinity of GDYO-QDs with a layer spacing of $0.36 \mathrm{~nm}$, which is in agreement with the interlayer spacing of GDY. [41] AFM image shows the typical topographic height of GDYO-QDs is in the range of 3-4 $\mathrm{nm}$ (Fig. 2c). The result is significantly confirmed by images of naked substrates (Fig. S1). The zeta potential of GDYO-QDs is $-35.1 \mathrm{mV}$ (Fig. S2), which is due to the presence of abundant hydrophilic groups (hydroxyl and carboxyl groups). The triple bonds in GDYO-QDs were determined by Raman spectroscopy. Fig. 2d shows the peaks at 1382 and $1598 \mathrm{~cm}^{-1}$ correspond to the 
D band and G band of GDY, GDYO and GDYO-QDs, respectively. The $\mathrm{I}_{\mathrm{D}} / \mathrm{I}_{\mathrm{G}}$ values of them were $0.867,0.896$ and 0.935 , respectively. The increasing value of $\mathrm{I}_{\mathrm{D}} / \mathrm{I}_{\mathrm{G}}$ indicates that the defects increases with the oxidation process of GDY. Two weak peaks at 1919 and $2188 \mathrm{~cm}^{-1}$ were attributed to the vibration of conjugated diyne links $(-\mathrm{C} \equiv \mathrm{C}-\mathrm{C} \equiv$ $\mathrm{C}-$ ), which is in agreement with the previous report.[42] It proves that GDYO-QDs have a carbon skeleton similar to that of GDY and GDYO (Fig. 2d).

The atomic ratio of $\mathrm{O} / \mathrm{C}$ in carbon materials plays an important role in their properties including heterogeneous electron transfer, chemical adsorption. [43, 44] Thus, X-ray photoelectron spectroscopy (XPS) analysis was used to illustrate the $\mathrm{O} / \mathrm{C}$ ratios during the preparation of GDYO-QDs (Fig. 2e, f and Fig. S3). As shown in Table S1, the O/C ratio of GDYO-QDs (46.13\%) was higher than GDY (26.93\%), indicating that the ultrasonic crushing process virtually led to the generation of oxygen-containing species, it is in agreement with the FT-IR results (Fig. S4). The C1s spectrum of GDYO-QDs and GDY can be deconvoluted into $\mathrm{C}-\mathrm{C}\left(\mathrm{sp}^{2}\right), \mathrm{C}-\mathrm{C}(\mathrm{sp}), \mathrm{C}-\mathrm{O}$, and $\mathrm{C}=\mathrm{O}$ at binding energies of 284.5, 285.2, 285.9, and $288.2 \mathrm{eV}$, respectively (Fig. 2e, f), which suggesting the similar carbon skeletons they have. Compared with GDY, the intensity of the peak at $284.5 \mathrm{eV}\left(\mathrm{sp}^{2}\right.$ - hybridized carbon) strengthened, while the peak at 285.2 $\mathrm{eV}$ (sp-hybridized carbon) obviously decreased, as shown in Fig. 2e. These results showed the partial oxidation of GDY and a certain percentage of the carbon triple bonds was broken during preparation of the GDYO-QDs. Moreover, a decrease of the $\mathrm{C}=\mathrm{O}$ content and an increase of the $\mathrm{C}-\mathrm{O}$ content in surface groups indicate the carboxylates were possibly reduced into lactones or ethers. [42] The O1s spectrum of GDY, GDYO and GDYO-QDs to confirm the hypothesis. (Fig. S5)

\subsection{Optical properties of GDYO-QDs.}

< Fig. 3.>

Fig. 3a and Fig. S6 show the absorption band of GDY, GDYO and GDYO-QDs decreased from $200 \mathrm{~nm}$ to $800 \mathrm{~nm}$, an insignificant absorption band at ca. $330 \mathrm{~nm}$ was observed in the spectra of GDYO-QDs, which is attributed to $n-\pi^{*}$ transitions of 
conjugated domains of GDYO-QDs. [48] The fluorescence quantum yield of GDYOQDs was calculated to be $14.6 \%$, the calculation is shown in Supporting Information. Fig. $3 b$ shows the maximum emission was observed at $446 \mathrm{~nm}$ when the excitation wavelength was $331 \mathrm{~nm}$. In 3D image (Fig. 3c), it shows the change of fluorescence intensity of GDYO- QDs under different excitation wavelengths (z axis: 280-380 nm) and emission wavelengths (x axis: $350-540 \mathrm{~nm}$ ). The positions of the excitation and emission peaks of GDYO-QDs confirm that the optimal excitation and emission wavelengths are about 330 and $450 \mathrm{~nm}$, respectively. The emission spectrum of GDYOQDs was recorded step by step in the excitation range from 301 to $371 \mathrm{~nm}$ with an increment of $10 \mathrm{~nm}$ (Fig. 3d). The emission peak red-shifted gradually with the increase of excitation wavelength. This phenomenon is due to the size-dependent band gap of GDYO-QDs and the existence of various surface defect states or different emission traps. [46] Fig. 3e shows the change of fluorescence intensity of GDYO-QDs in different concentrations of salt solution, indicating that it can tolerate high salt concentrations. By comparing the fluorescence properties of GDYO- QDs prepared in three different batches (Fig.S7), the small difference indicates that the preparation process is relatively stable. In addition, the change of fluorescence intensity of GDYOQDs in 14 days was studied, and it was found that the quantum dots could still maintain good fluorescence properties after being stored for a long time (Fig.S8). Fig. 3f shows the fluorescence intensity of GDYO-QDs changed very little after 1 hour of continuous UV irradiation, indicating an excellent resistance to photobleaching of GDYO-QDs.

3.3. Analytical performance for $\mathrm{Fe}^{3+}$ and AA detection under optimized condition.

< Fig. 4.>

A fluorescence sensor based GDYO-QDs were established for $\mathrm{Fe}^{3+}$ and AA detection. The experimental conditions including the $\mathrm{pH}$ value of the assay and the reaction time were investigated and optimized, as elaborated in Supporting Information (Fig.9-12). Fig. 4a shows the fluorescence spectra of GDYO-QDs solution with the addition of different $\mathrm{Fe}^{3+}$ concentrations. The fluorescence intensity of GDYO-QDs at $446 \mathrm{~nm}$ 
decreased with the increase of $\mathrm{Fe}^{3+}$ concentration. The curves of quenching ratio $\left(\mathrm{F}_{0}-\right.$ $\mathrm{F}) / \mathrm{F}$ and $\mathrm{Fe}^{3+}$ concentration from 0 to $300 \mu \mathrm{mol} \mathrm{L}{ }^{-1}$ were performed (Fig. $4 \mathrm{~b}$ ), where $\mathrm{F}_{0}$ and $\mathrm{F}$ are the fluorescence intensity of GDYO-QDs solution before and after the addition of $\mathrm{Fe}^{3+}$, respectively. The limit of detection (LOD) was $95 \mathrm{nmol} \mathrm{L}^{-1}(\mathrm{~S} / \mathrm{N}=3$, $\mathrm{R}^{2}=0.9889$ ), with a linear range of $0.25-200 \mu \mathrm{mol} \mathrm{L} \mathrm{L}^{-1}$ was obtained. LOD is much lower than the Environmental Protection Agency (US EPA) guideline $\left(5.37 \mu \mathrm{mol} \mathrm{L}^{-1}\right)$ in biological serum and the linear range meets the needs of detection in our daily life. A comparison of different QD based fluorescent sensors for $\mathrm{Fe}^{3+}$ detection is summarized in Table S2; our sensor was much sensitive than most of the other fluorescent sensors.

AA was used to recover the fluorescence intensity of GDYO-QDs, because of AA can reduce $\mathrm{Fe}^{3+}$ to $\mathrm{Fe}^{2+}$ (Fig. 4c). Notably, AA had no effect on the fluorescence intensity of GDYO-QDs when without $\mathrm{Fe}^{3+}$ (Fig. S13). The fluorescence recovery tended to be stable with the addition of AA after 4 minutes (Fig. S14). With the increase of AA concentration, the fluorescence of GDYO-QDs at $446 \mathrm{~nm}$ recovered gradually, the fluorescence recovery rate was about $85 \%$. The LOD was $2.5 \mu \mathrm{mol} \mathrm{L}{ }^{-1}\left(\mathrm{~S} / \mathrm{N}=3, \mathrm{R}^{2}\right.$ $=0.9906)$, with a linear range of $10-500 \mu \mathrm{mol} \mathrm{L}-1$ (Fig. $4 \mathrm{~d}$ ). In addition, the reversible fluorescence change of GDYO-QDs after adding AA in the presence of $\mathrm{Fe}^{3+}$ was also investigated, as shown in Figure S12. The fluorescence intensity of GDYO-QDs was quenched rapidly after the addition of $\mathrm{Fe}^{3+}$. After adding AA, the fluorescence intensity of GDYO-QDs was recovered within 2 min (Fig. S15), and there was a good recovery in three consecutive cycles. The results showed that the system was reversible and could be recycled for at least 3 times for simultaneous determination of $\mathrm{Fe}^{3+}$ and AA.

The selectivity of the sensor was investigated, two groups of control experiments were carried out. Firstly, $100 \mu \mathrm{mol} \mathrm{L}{ }^{-1}$ (Fig. 4e) and $1000 \mu \mathrm{mol} \mathrm{L}^{-1}$ (Fig. S16) of biological and environment-related metal ions were added to the GDYO-QDs solution, including $\mathrm{Fe}^{3+}, \mathrm{Fe}^{2+}, \mathrm{Cu}^{2+}, \mathrm{Mn}^{2+}, \mathrm{Cr}^{3+}, \mathrm{Cd}^{2+}, \mathrm{Ca}^{2+}, \mathrm{Mg}^{2+}, \mathrm{Na}^{+}, \mathrm{Ni}^{2+}, \mathrm{Pb}^{2+}, \mathrm{Al}^{3+}, \mathrm{Zn}^{2+}$ and the mixed solution of various metal ions, the fluorescence intensity changes were recorded. Obviously, it can be seen that the quenching effect of $\mathrm{Fe}^{3+}$ on GDYO-QDs reached more than $80 \%$, which shows a good selectivity for $\mathrm{Fe}^{3+}$. Moreover, the 
selectivity of GDYO QDs for AA over other interference substances (L-Threonine (LThr), Glutamic acid (Glu), Carbonic Anhydrase (CA), Homocysteine (Hcy), Glutathione (GSH), Proline (Pro), L-Valine (L-Val), L-Cysteine (L-Cys), L-Alanine (LAla), DL- Phenylalanine (DL-Phe), Uric acid (UA), Dopamine (DA)) was also investigated, as shown in Fig. 4f. The result shows that the fluorescence recovery of GDYO-QDs/ $/ \mathrm{Fe}^{3+}$ sensor by AA is much higher than that of other interfering substances. At the same time, in the presence of metal ions and other interfering organic compounds, the fluorescence of the system changed slightly, which shows high selectivity for $\mathrm{Fe}^{3+}$ and AA (Fig. S17). In other words, our sensor shows a high anti-interference capability.

\subsection{Mechanism of fluorescence quenching by $\mathrm{Fe}^{3+}$.}

< Fig. 5.>

On the basis of previous reports, the quenching effect is mainly attributed to the action of inner filter effect (IFE) or photoinduced electron transfer (PET). [3, 47] To further verify this hypothesis, the reaction process of GDYO-QDs with $\mathrm{Fe}^{3+}$ in the aspects of IFE and PET was investigated. In order to verify the mechanism of IFE, we firstly studied the optical properties of GDYO-QDs and $\mathrm{Fe}^{3+}$. It can be seen from Fig. 5a that $\mathrm{Fe}^{3+}$ has a strong absorption in the range of 260-400 nm, overlapping with the excitation band of GDYO-QDs (331 nm), which leads to the formation of IFE between GDYO-QDs and $\mathrm{Fe}^{3+}$. [3, 48] Fig. 5b shows the time-resolved fluorescence decay spectra of GDYO-QDs with 0,50 and $100 \mu \mathrm{mol} \mathrm{L}^{-1} \mathrm{of} \mathrm{Fe}^{3+}$, a double exponential decay function recorded the fluorescence decay time. The fluorescence decay time of GDYOQDs is 10.22 ns without $\mathrm{Fe}^{3+}$. After adding $\mathrm{Fe}^{3+}$, whose concentrations were 50 and 100 $\mu \mathrm{mol} \mathrm{L} \mathrm{L}^{-1}$, the corresponding decay time were 10.36 and $10.47 \mathrm{~ns}$, respectively. The fluorescence decay time changed insignificantly after the addition of $\mathrm{Fe}^{3+}$, indicating quenching mechanism is not only due to IFE, because IFE is a static quenching process that does not cause disturbance of excited states of fluorophores. $[49,50]$ We made an additional study on the effect of IFE on the quenching process, according to absorption 
characteristics and the cuvette geometry (Fig. 5c), the IFE on GDYO-QDs and $\mathrm{Fe}^{3+}$ was corrected by the following equation. [51]

$$
C F=\frac{F_{c o r}}{F_{\text {obsd }}}=\frac{2.3 \mathrm{~d} A_{\text {ex }}}{1-10^{-d A_{e x}}} \times 10^{g A_{e m}} \times\left[2.3 s A_{e m} /\left(1-10^{-s A_{e m}}\right)\right]
$$

Where, $\mathrm{CF}$ is the corrected factor; $\mathrm{F}_{\text {cor }}$ and $\mathrm{F}_{\text {obsd }}$ severally represent the corrected fluorescence intensity by removing IFE from $F_{\text {obsd }}$ and the observed fluorescence intensity of GDYO-QDs. $\mathrm{A}_{\mathrm{ex}}$ and $\mathrm{A}_{\mathrm{em}}$ represent the absorbance per centimeter of GDYO- QDs at the excitation wavelength and the emission wavelength, respectively. Fig. 5c shows the quenching efficiency of observed $\left(\mathrm{Q}_{\mathrm{obsd}}\right)$ and corrected $\left(\mathrm{Q}_{\mathrm{cor}}\right)$ fluorescence of GDYO-QDs at different concentrations of $\mathrm{Fe}^{3+}$. Table S3 summarizes the detailed calculation process and results. From the above results show a $35 \%$ of quenching efficiency of $\mathrm{Fe}^{3+}$ to GDYO-QDs can be obtained via IFE, which indicates the quenching of GDYO-QDs by $\mathrm{Fe}^{3+}$ was not completely dependent on IFE.

To verify the mechanism of PET, the electron bandgap (Eg) and valence band (VB) of GDYO-QDs were studied (Fig. 5d, e). By using the Tauc plot (Fig. 5d) in UV-Vis absorption spectrum (Fig. 3a), the direct electron band gap of GDYO-QDs was $1.65 \mathrm{eV}$. Through the XPS valence band spectrum (Fig. 5e), the VB of GDYO-QDs was calculated to be $2.01 \mathrm{eV}$ (EVB) vs Normal Hydrogen Electrode (NHE). According to the formula: $E_{C B}=E_{V B}-E_{g}$, the conduction band (CB) is $0.36 \mathrm{eV}$ vs NHE. While the standard electrode potential of $\mathrm{Fe}^{3+} / \mathrm{Fe}^{2+}$ is $0.77 \mathrm{eV}$ vs NHE, which is located between VB and CB of GDYO- QDs. When light excites the GDYO-QDs, the electrons of $\mathrm{VB}$ are excited to $\mathrm{CB}$; consequently, these electrons transfer to the d-orbit of $\mathrm{Fe}^{3+}$ instead of going back to VB, thus fluorescence quenching is caused by PET process, as illustrated in Fig. 5f. [52, 53] In summary, the fluorescence quenching of GDYOquantum dots by $\mathrm{Fe}^{3+}$ is caused by the synergistic effect of IFE and PET.

3.5. Real application of GDYO-QDs for analysis of $\mathrm{Fe}^{3+}$ and AA in fetal bovine serum samples.

The potential of biological application was carried out by analyzing $\mathrm{Fe}^{3+}$ in human 
serum samples. Since the concentrations of $\mathrm{Mg}^{2+}$ and $\mathrm{Ca}^{2+}$ are usually 100 times higher than $\mathrm{Fe}^{3+}$ in human serum samples, we firstly studied the selectivity of the assay towards $\mathrm{Fe}^{3+}$ in the presence of $\mathrm{Mg}^{2+}\left(10 \mathrm{mmol} \mathrm{L}^{-1}\right)$ and $\mathrm{Ca}^{2+}\left(10 \mathrm{mmol} \mathrm{L}^{-1}\right)$. The results indicated no obvious effect was caused by $\mathrm{Mg}^{2+}$ and $\mathrm{Ca}^{2+}$ on the fluorescence intensity of GDYO-QDs (Fig. S18). In order to verify the accuracy of this method, atomic absorption spectrometry (AAS) was used as the standard method for the determination of $\mathrm{Fe}^{3+}$ in human serum. Table 1 shows the related recovery results of the above samples, which is in the range of $98.77 \%-102.66 \%$. At the same time, with the nitrate of $\mathrm{Fe}^{3+}$ as the standard solution, the unknown content of $\mathrm{Fe}^{3+}$ in human serum was determined by standard addition method. In addition, the detection and analysis of AA in fetal bovine serum was also carried out. GDYO-QDs of $200 \mu \mathrm{mol} \mathrm{L}-1$ was added to fetal bovine serum as sample solution. Three different concentrations of AA (50, 200 and $400 \mu \mathrm{mol} \mathrm{L}^{-1}$ ) added to the sample solution. As shown in Table S4, the recovery range of the relevant samples is $97.68 \%-103.27 \%$. The relative standard deviation $(n=3)$ is less than $4.21 \%$. The good recovery rate shows the reliability of the assay, the low deviation proves that the sensor has the potential to be used in clinical detection.

$<$ Table 1.>

\section{Conclusions}

GDYO-QDs were fabricated through acid-oxidation treatment and ultrasound method, their optical property was investigated. The fluorescence of GDYO-QDs can be quenched efficiently by $\mathrm{Fe}^{3+}$, and can be recovered by AA, which can be utilized as a fluorescent sensor for $\mathrm{Fe}^{3+}$ and $\mathrm{AA}$ detection. The results showed a selective and sensitive sensor for $\mathrm{Fe}^{3+}$ and AA detection was obtained, the LOD is $95 \mathrm{nmol} \mathrm{L}{ }^{-1}$, with range of $0.25-200 \mu \mathrm{mol} \mathrm{L}{ }^{-1}$, (AA: LOD is $2.5 \mu \mathrm{mol} \mathrm{L}^{-1}$, with range of $10-500 \mu \mathrm{mol} \mathrm{L}^{-1}$ ). In addition, this sensor was applied successfully for $\mathrm{Fe}^{3+}$ detection in fetal bovine serum sample. Finally, the quenching mechanism by $\mathrm{Fe}^{3+}$ was proposed as that the synergistic effect between IFE and PET. Our present study provides a newly carbon-based fluorescent sensor for rapid, highly selective, and sensitive detection of $\mathrm{Fe}^{3+}$ and AA. 
In the present work, the quantum yield of GDYO-QDs is not high, which limits the sensitivity of detection, further work will be focused on the improvement of their quantum yield.

\section{Acknowledgements}

This work was financially supported by the National Natural Science Foundation of China (21501106), the Scientific Research Foundation for the Returned Overseas Chinese Scholars and Qingdao Municipal Science and Technology Commission (16-51-86-jch, 19-6-2-73-cg), Chemistry Faculty Talents Foundation of Qingdao University of Science and Technology.

\section{References}

[1] A. Syal, D. Sud, Development of highly selective novel fluorescence quenching probe based on $\mathrm{Bi}_{2} \mathrm{~S}_{3}-\mathrm{TiO}_{2}$ nanoparticles for sensing the Fe(III), Sens. Actuators BChem. 266 (2018) 1-8.

[2] Kardar, Z. S., Shemirani, F., \& Zadmard, R., Determination of iron (II) and iron (III) via static quenching of the fluorescence of tryptophan-protected copper nanoclusters, Microchim. Acta, 187 (2020) 1-9.

[3] X. Guo, G. Yue, J. Huang, C. Liu, Q. Zeng, L. Wang, Label-Free Simultaneous Analysis of $\mathrm{Fe}(\mathrm{III})$ and Ascorbic Acid Using Fluorescence Switching of Ultrathin Graphitic Carbon Nitride Nanosheets, Acs Applied Materials \& Interfaces. 10 (2018) 26118-26127.

[4] Cao H , Chen Z, Zheng H , et al. Copper nanoclusters as a highly sensitive and selective fluorescence sensor for ferric ions in serum and living cells by imaging $[\mathrm{J}]$, Biosensors \& Bioelectronics. 62 (2014) 189-195.

[5]Aptasensor Based on $\mathrm{MoS}_{2}$ Quantum Dots with Upconversion Fluorescence for Microcystin-LR Detection via the Inner Filter Effect[J], ACS Sustainable Chemistry And Engineering. 8(2020) 29:10939-10946.

[6] G.T. Sucak, Z.A. Yegin, Z.N. zkurt, Z. Ak, T. Karakan, G.J.B.M.T. Akyol, The role of liver biopsy in the workup of liver dysfunction late after SCT: is the role of iron overload underestimated?, Bone Marrow Transplant. 42 (2008) 461-467. 
[7] Weinstein, D.A., Inappropriate expression of hepcidin is associated with iron refractory anemia: implications for the anemia of chronic disease, Blood. 100 (2002) 3776-3781.

[8] N. Narayanaswamy, T.J.S. Govindaraju, Aldazine-based colorimetric sensors for $\mathrm{Cu}^{2+}$ and $\mathrm{Fe}^{3+}$, Sens. Actuators B-Chem 161 (2012) 304-310.

[9] A. Spolaor, P. Vallelonga, J. Gabrieli, G. Cozzi, C. Boutron, C. Barbante, Determination of $\mathrm{Fe}^{2+}$ and $\mathrm{Fe}^{3+}$ species by FIA-CRC-ICP-MS in Antarctic ice samples, J. Anal. At. Spectrom. 27 (2012) 310-317.

[10] A. Bobrowski, K. Nowak, J. Zarębski, Application of a bismuth film electrode to the voltammetric determination of trace iron using a $\mathrm{Fe}(\mathrm{III})$ - TEA - BrO3-catalytic system, Anal. Chem. 382 (2005) 1691-1697.

[11] Liang, C. , Lan, Y., Sun, Z. , Zhou, L., Qin, X., Synthesis of carbon quantum dots with iron and nitrogen from passiflora edulis and their peroxidase-mimicking activity for colorimetric determination of uric acid. Microchim. Acta, 187(2020).

[12] N. Sui, F. Liu, K. Wang, F. Xie, L. Wang, J. Tang, M. Liu, W.W. Yu, Nano Au-Hg amalgam for $\mathrm{Hg}^{2+}$ and $\mathrm{H}_{2} \mathrm{O}_{2}$ detection, Sens. Actuators B-Chem. 252 (2017) 1010-1015. [13] A. Umar, M.S. Chauhan, S. Chauhan, R. Kumar, P. Sharma, K.J. Tomar, R. Wahab, A. Al-Hajry, D. Singh, Applications of $\mathrm{ZnO}$ nanoflowers as antimicrobial agents for Escherichia coli and enzyme-free glucose sensor, J Biomed Nano. 9 (2013) 1794-1802. [14] L. Long, L. Zhou, L. Wang, S. Meng, A. Gong, C. Zhang, A ratiometric fluorescent probe for iron(III) and its application for detection of iron(III) in human blood serum, Anal Chim Acta. 812 (2014) 145-151.

[15] M. Cacciari, M.L. Mangano, P. Nason, Gluon PDF constraints from the ratio of forward heavy-quark production at the LHC at $\sqrt{s}=2$ and $13 \mathrm{TeV}$, Eur Phys J C Part Fields. 75 (2015) 610.

[16] L. Qiu, C. Zhu, H. Chen, M. Hu, W. He, Z. Guo, A turn-on fluorescent Fe(III) sensor derived from an anthracene-bearing bisdiene macrocycle and its intracellular imaging application, Chem Commun (Camb). 50 (2014) 4631-4634.

[17] Omer K M, Hassan A Q. Chelation-enhanced fluorescence of phosphorus doped carbon nanodots for multi-ion detection, Microchim. Acta, 184 (2017) 2063-2071. 
[18] Xiao, Hailian, Wang, Lina, Xie, Fengxia, Yu, William, W., S.J.M.A.A.I.J.f. Physical, C.M.o. Analysis, Ultrasensitive aptamer-based thrombin assay based on metal enhanced fluorescence resonance energy transfer, Microchim. Acta. 183 (2016) 15631570.

[19] B. Shi, Y. Su, L.L. Zhang, M. Huang, R. Liu, S.J. Zhao, Nitrogen and Phosphorus Co-doped Carbon Nanodots as a Novel Fluorescent Probe for Highly Sensitive Detection of $\mathrm{Fe}^{3+}$ in Human Serum and Living Cells, Acs Applied Materials \& Interfaces. 8 (2016) 10717-10725.

[20] J. Shangguan, J. Huang, D. He, X. He, K. Wang, R. Ye, X. Yang, T. Qing, J. Tang, Highly Fe(III)-Selective Fluorescent Nanoprobe Based on Ultrabright N/P Codoped Carbon Dots and Its Application in Biological Samples, Anal Chem. 89 (2017) 74777484.

[21] S. Li, Y. Li, J. Cao, J. Zhu, L. Fan, X. Li, Sulfur-doped graphene quantum dots as a novel fluorescent probe for highly selective and sensitive detection of Fe(III), Anal Chem. 86 (2014) 10201-10207.

[22] K.D. Wegner, N.J. Hildebrandt, Quantum dots: bright and versatile in vitro and in vivo fluorescence imaging biosensors, Chem. Soc. Rev. 44 (2015) 4792-4834.

[23] P. Zuo, X. Lu, Z. Sun, Y. Guo, H. He, A review on syntheses, properties, characterization and bioanalytical applications of fluorescent carbon dots, Microchim. Acta 183 (2015) 519-542.

[24] R. Liu, D. Wu, S. Liu, K. Koynov, W. Knoll, Q. Li, An aqueous route to multicolor photoluminescent carbon dots using silica spheres as carriers, Angew Chem Int Ed Engl. 48 (2009) 4598-4601.

[25] S.N. Baker, G.A. Baker, Lumineszierende Kohlenstoff-Nanopunkte: Nanolichtquellen mit Zukunft, Angewandte Chemie. 122 (2010) 6876-6896.

[26] S. Xu, et al. Lysosome-targeted ratiometric fluorescent sensor for monitoring $\mathrm{pH}$ in living cells based on one-pot-synthesized carbon dots, Microchimica Acta 187 (2020) $1-9$. 
[27] S. Xu, Y. Liu, H. Yang, K. Zhao, J. Li, A.J. Deng, Fluorescent nitrogen and sulfur co-doped carbon dots from casein and their applications for sensitive detection of $\mathrm{Hg}$ ${ }^{2+}$ and biothiols and cellular imaging, Anal. Chim Acta. 964 (2017) 150-160.

[28] Omer, K. M. , Hassan, A. Q., Chelation-enhanced fluorescence of phosphorus doped carbon nanodots for multi-ion detection. Microchim. Acta, 184 (2017) 20632071.

[29] Y.L. Zhang, L. Wang, H.C. Zhang, Y. Liu, S.T.J. Lee, Graphitic carbon quantum dots as a fluorescent sensing platform for highly efficient detection of $\mathrm{Fe}^{3+}$ ions, Rsc Advances. 3 (2013) 3733-3738.

[30] C. Sun, Y. Zhang, P. Wang, Y. Yang, Y. Wang, J. Xu, Y. Wang, W.W.J. Yu, Synthesis of Nitrogen and Sulfur Co-doped Carbon Dots from Garlic for Selective Detection of $\mathrm{Fe}^{3+}$, Nanoscale Res Lett. 11 (2016) 110.

[31] Y. Liang, L. Xu, K. Tang, Y. Guan, T. Wang, H. Wang, W.W. Yu, Nitrogen-doped carbon dots used as an “on - off - on” fluorescent sensor for $\mathrm{Fe}^{3+}$ and glutathione detection, Dyes and Pigments. 178 (2020) 178:108358.

[32] G. Li, Y. Li, H. Liu, Y. Guo, Y. Li, D. Zhu, Architecture of graphdiyne nanoscale films, Chem Commun (Camb). 46 (2010) 3256-3258.

[33] C. Wang, P. Yu, S. Guo, L. Mao, H. Liu, Y. Li, Graphdiyne oxide as a platform for fluorescence sensing, Chem Commun (Camb). 52 (2016) 5629-5632.

[34] H. Wang, K. Deng, J. Xiao, C. Li, S. Zhang, X. Li, A sandwich-type photoelectrochemical sensor based on tremella-like graphdiyne as photoelectrochemical platform and graphdiyne oxide nanosheets as signal inhibitor, Sens. Actuators B-Chem. 304 (2020).

[35] N. Parvin, Q. Jin, Y. Wei, R. Yu, B. Zheng, L. Huang, Y. Zhang, L. Wang, H. Zhang, M.J. Gao, Few-Layer Graphdiyne Nanosheets Applied for Multiplexed Real-Time DNA Detection, Adv. Mater. 29 (2017) 1606755.1606751-1606755.1606757.

[36] M. Long, L. Tang, D. Wang, Y. Li, Z.J. Shuai, Electronic Structure and Carrier Mobility in Graphdiyne Sheet and Nanoribbons: Theoretical Predictions, Acs Nano. 5 (2011) 2593-2600. 
[37] J. Jin, M. Guo, J. Liu, J. Liu, H. Zhou, J. Li, L. Wang, H. Liu, Y. Li, Y.J. Zhao, Interfaces, Graphdiyne Nanosheet-Based Drug Delivery Platform for Photothermal/Chemo-therapy Combination Treatment of Cancer, Acs Appl. Mater. Interfaces. (2018) acsami.7b17219.

[38] W.W. Yu, Y.A. Wang, X.J. Peng, Formation and Stability of Size-, Shape-, and Structure-Controlled CdTe Nanocrystals: Ligand Effects on Monomers and Nanocrystals, Chem. Mater.15 (2003) 4300-4308.

[39] H. Min, Y. Qi, Y. Chen, Y. Zhang, G.N.J., Synthesis and Imaging of Biocompatible Graphdiyne Quantum Dots, Acs Appl. Mater. Interfaces. 11 (2019) 10.1021.

[40] Graphdiyne Oxides as Excellent Substrate for Electroless Deposition of Pd Clusters with High Catalytic Activity, J. Am. Chem. Soc. 137(2015) 16:5260-5263.

[41] P. Kuang, B. Zhu, Y. Li, H. Liu, J. Yu, K. Fan, Graphdiyne: a superior carbon additive to boost the activity of water oxidation catalysts, Nanoscale Horizons 3 (2018) 317-326.

[42] S. Guo, H. Yan, F. Wu, L. Zhao, P. Yu, H. Liu, Y. Li, L. Mao, Graphdiyne as Electrode Material: Tuning Electronic State and Surface Chemistry for Improved Electrode Reactivity, Anal Chem. 89 (2017) 13008-13015.

[43] V. Georgakilas, J.N. Tiwari, K.C. Kemp, J.A. Perman, A.B. Bourlinos, K.S. Kim, R.J.C.r. Zboril, Noncovalent functionalization of graphene and graphene oxide for energy materials, biosensing, catalytic, and biomedical applications, Chem. Rev. 116 (2016) 5464-5519.

[44] S. Ning, L. Wang, X. Wu, X. Li, S. Jing, H. Xiao, M. Liu, J. Wan, W.W.J. Yu, Polyethylenimine modified magnetic graphene oxide nanocomposites for $\mathrm{Cu}^{2+}$ removal, Rsc. Adv. 5 (2014) 746-752.

[45] A. Mewada, S. Pandey, S. Shinde, N. Mishra, G. Oza, M. Thakur, M. Sharon, M. Sharon, Green synthesis of biocompatible carbon dots using aqueous extract of Trapa bispinosa peel, Mater Sci Eng C Mater Biol Appl. 33 (2013) 2914-2917.

[46] J. Peng, W. Gao, B.K. Gupta, Z. Liu, R. Romero-Aburto, L. Ge, L. Song, L.B. Alemany, X. Zhan, G. Gao, S.A. Vithayathil, B.A. Kaipparettu, A.A. Marti, T. Hayashi, 
J.J. Zhu, P.M. Ajayan, Graphene quantum dots derived from carbon fibers, Nano Lett. 12 (2012) 844-849.

[47] Y. Li, J. Cai, F. Liu, H. Yu, F. Lin, H. Yang, Y. Lin, S. Li, Highly crystalline graphitic carbon nitride quantum dots as a fluorescent probe for detection of $\mathrm{Fe}(\mathrm{III})$ via an innner filter effect, Microchim. Acta 185 (2018) 134.

[48] G.N. Kalantzopoulos, F. Lundvall, S. Checchia, A. Lind, D.S. Wragg, H. Fjellvag, B. Arstad, In Situ Flow MAS NMR Spectroscopy and Synchrotron PDF Analyses of the Local Response of the Bronsted Acidic Site in SAPO-34 during Hydration at Elevated Temperatures, Chemphyschem. 19 (2018) 519-528.

[49] W. Kong, D. Wu, L. Xia, X. Chen, G. Li, N. Qiu, G. Chen, Z. Sun, J. You, Y. Wu, Carbon dots for fluorescent detection of alpha-glucosidase activity using enzyme activated inner filter effect and its application to anti-diabetic drug discovery, Anal Chim Acta. 973 (2017) 91-99.

[50] X. Zhu, T. Zhao, Z. Nie, Y. Liu, S. Yao, Non-redox modulated fluorescence strategy for sensitive and selective ascorbic acid detection with highly photoluminescent nitrogen-doped carbon nanoparticles via solid-state synthesis, Anal Chem. 87 (2015) 8524-8530.

[51] S.J. Xiao, X.J. Zhao, P.P. Hu, Z.J. Chu, C.Z. Huang, L. Zhang, Highly Photoluminescent Molybdenum Oxide Quantum Dots: One-Pot Synthesis and Application in 2,4,6-Trinitrotoluene Determination, ACS Appl Mater Interfaces. 8 (2016) 8184-8191.

[52] L. Guo, Y. Liu, R. Kong, G. Chen, Z. Liu, F. Qu, L. Xia, W. Tan, A Metal-Organic Framework as Selectivity Regulator for Fe(III) and Ascorbic Acid Detection, Anal Chem. 91 (2019) 12453-12460.

[53] Y. Yan, C. Zhang, W. Gu, C. Ding, X. Li, Y. Xian, Facile Synthesis of WaterSoluble $\mathrm{WS}_{2}$ Quantum Dots for Turn-On Fluorescent Measurement of Lipoic Acid, J. Phys. Chem. C. 120 (2016) 12170-12177. 
Fig. 1. Synthesis of GDYO-QDs and fluorescent detection of $\mathrm{Fe}^{3+}$ and AA.
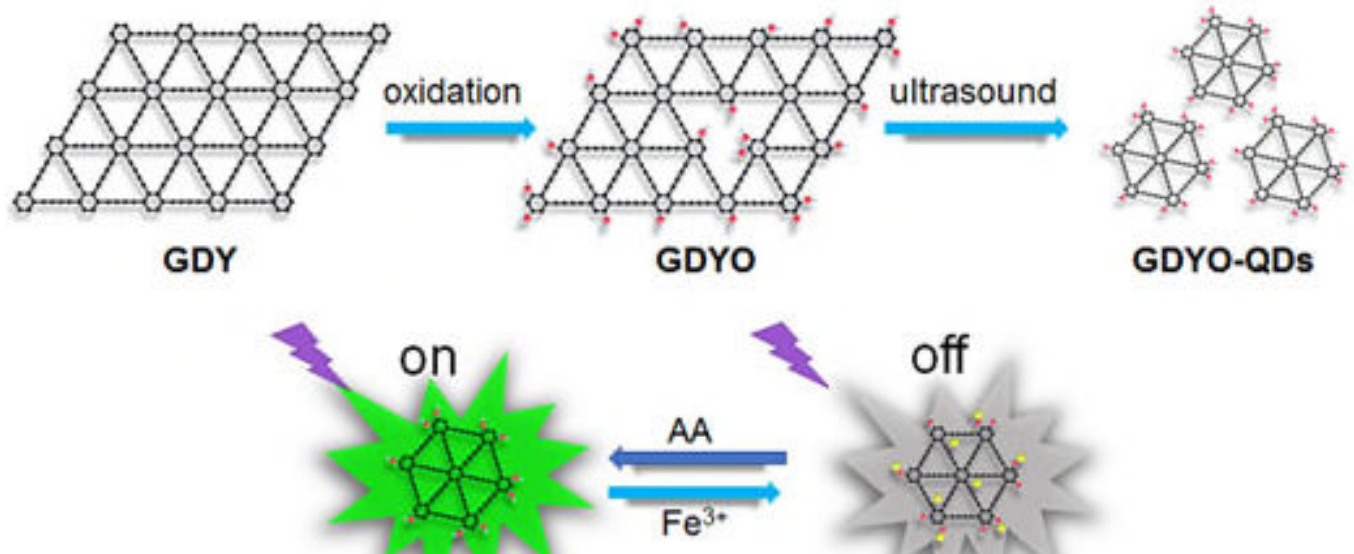

Fig. 2. (a) TEM image of GDYO-QDs. Inset: size distribution of GDYO-QDs. (b) High resolution TEM images of GDYO-QDs. (c) AFM images of GDYO-QDs. (d) Raman spectroscopy of GDY and GDYO-QDs. High-resolution C1s spectra of (e) GDY and (f) GDYO-QDs.
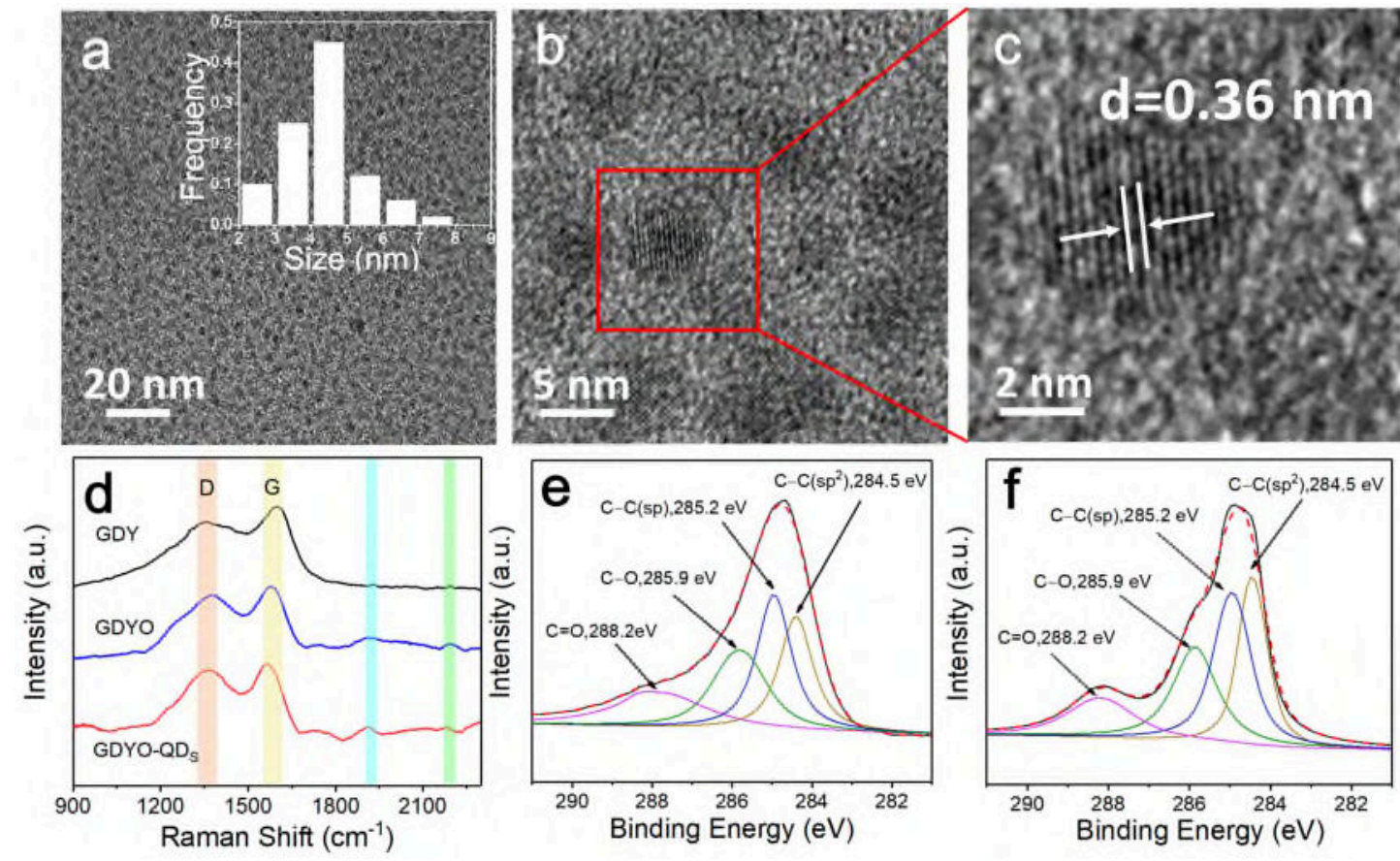
Fig 3. (a) UV-vis absorption spectra of GDY and GDYO-QDs. Inset: photographs of GDYO-QDs solution (dispersed in water) under sunlight (left) and under $360 \mathrm{~nm} \mathrm{UV}$ irradiation (right). (b) Excitation and emission spectra of GDYO-QDs. (c) 3D fluorescence spectra of GDYO-QDs. (d) Fluorescence spectra of GDYO-QDs excited at different wavelengths. (e) Fluorescence intensity (at $446 \mathrm{~nm}$ ) of GDYO-QDs influenced by different concentrations of salt solutions. (n=3) (f) Photo stability of GDYO-QDs under irradiation for $1 \mathrm{~h}$.
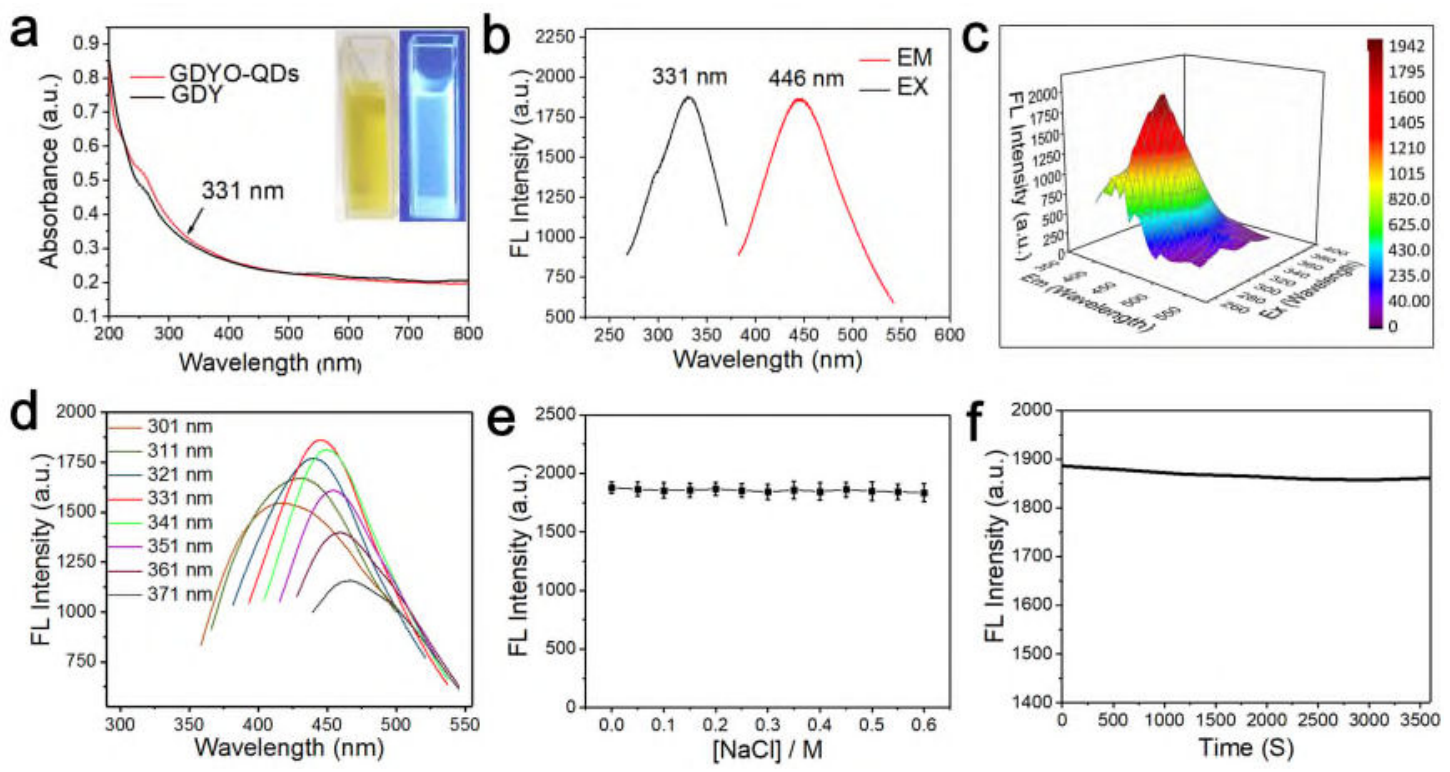
Fig. 4. (a) Fluorescence spectra of GDYO-QDs for the detection of different concentrations of $\mathrm{Fe}^{3+}$ (from top to bottom: 0 - $300 \mu \mathrm{mol} \mathrm{L} \mathrm{L}^{-1}$ ). (b) Calibration curve of $\left(\mathrm{F}_{0}-\mathrm{F}\right) / \mathrm{F}$ versus $\mathrm{Fe}^{3+}$ concentration, the inset is the calibration curve of $\left(\mathrm{F}_{0}-\mathrm{F}\right) / \mathrm{F}$ and low concentration $\mathrm{Fe}^{3+}\left(0.25-200 \mu \mathrm{mol} \mathrm{L}{ }^{-1}\right)$. (c) Fluorescence emission spectra of GDYO-QDs and $\mathrm{Fe}^{3+}\left(200 \mu \mathrm{mol} \mathrm{L}{ }^{-1}\right)$ with different concentrations of AA (from bottom to top: $\left.0-1000 \mathrm{nmol} \mathrm{L}{ }^{-1}\right)$. (d) Calibration curve of $\left(\mathrm{F}-\mathrm{F}_{0}\right) / \mathrm{F}_{0}$ versus concentration of $\mathrm{AA}$, the inset is the calibration curve of $\left(\mathrm{F}-\mathrm{F}_{0}\right) / \mathrm{F}_{0}$ versus concentration of $\mathrm{AA}$ and low concentration AA $\left(10-500 \mu \mathrm{mol} \mathrm{L}{ }^{-1}\right)$. (e) Selective response of aqueous GDYO-QDs towards different metal ions (the concentrations of metal ions were all $50 \mu \mathrm{mol} \mathrm{L}^{-1}$ ), (f) Selective response of aqueous GDYO-QDs towards other interference substances. (concentrations of AA and interference substances were all $\left.400 \mu \mathrm{mol} \mathrm{L} \mathrm{L}^{-1}\right),(\lambda \mathrm{ex}=331$ $\mathrm{nm}) . \mathrm{F}_{0}$ and $\mathrm{F}$ are the fluorescence intensities of GDYO-QDs at $446 \mathrm{~nm}$ in the absence and presence of $\mathrm{Fe}^{3+}$, respectively. (n=3)
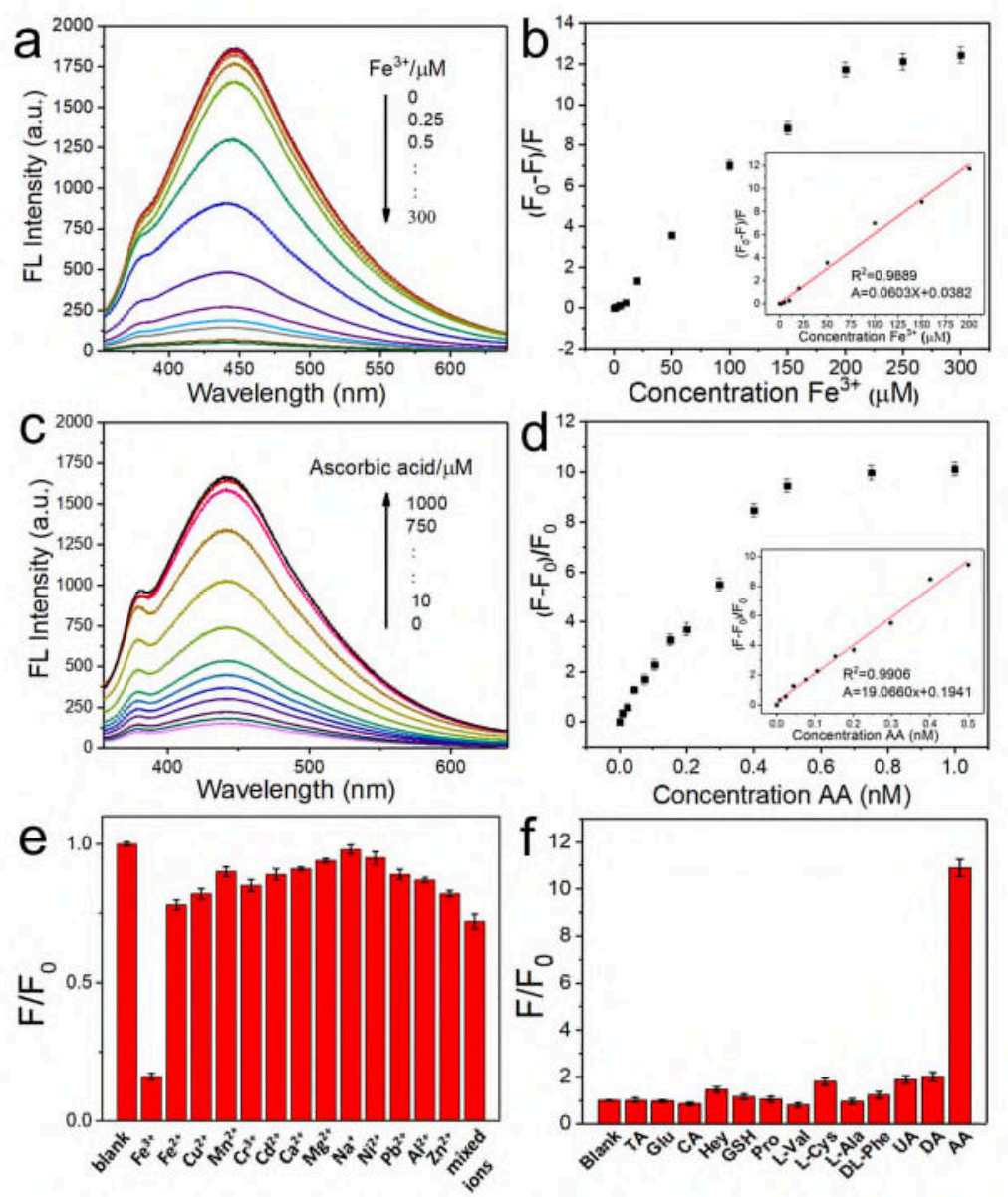
Fig. 5. (a) UV-vis absorption spectra of GDYO-QDs (black) and $\mathrm{Fe}^{3+}$ (blue), fluorescence spectrum of GDYO-QDs (red). (b) The fluorescence lifetime of GDYOQDs without $\mathrm{Fe}^{3+}$, with 50 and $100 \mu \mathrm{mol} \mathrm{L} \mathrm{L}^{-1} \mathrm{Fe}^{3+}$. (c) Quench efficient of observed $\left(\mathrm{Q}_{\text {obsd }}\right)$ and corrected $\left(\mathrm{Q}_{\text {cor }}\right)$ fluorescence of GDYO-QDs with $\mathrm{Fe}^{3+}$, which was calculated according to equation: $\mathrm{Q}_{\mathrm{F}}=\left(\mathrm{F}_{0}-\mathrm{F}\right) / \mathrm{F}_{0}$. Inset: Parameters used for the correction of the inner filter effect: $\mathrm{I}_{0}$ represents the excitation beam; $\mathrm{s}$ is the thickness of the excitation beam $(0.10 \mathrm{~cm})$; $\mathrm{g}$ is the distance between the edge of the excitation beam and the edge of the cuvette $(0.40 \mathrm{~cm})$; $d$ is the width of the cuvette $(1.00 \mathrm{~cm})$ and $\mathrm{F}$ is the observed fluorescence beam. (d) A plot of $(\alpha \mathrm{h} v)^{1 / 2}$ versus photon energy (Eg) of GDYO-QDs, and the dotted line is a linear fitting. (e) XPS valence band spectrum of GDYO-QDs, the dotted line is a linear fitting. (f) Schematic diagram of PET process mechanism between $\mathrm{Fe}^{3+}$ and GDYO-QDs.
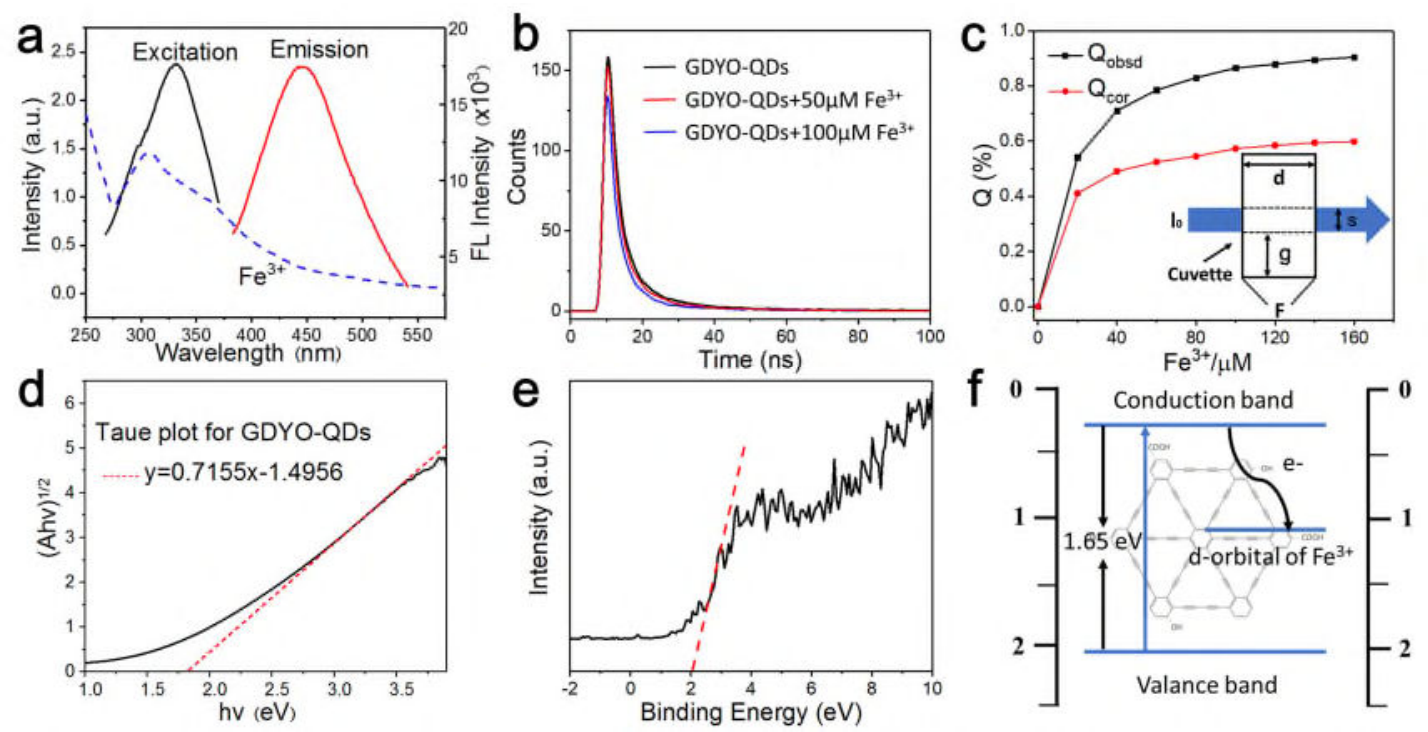
Table 1. Recoveries of $\mathrm{Fe}^{3+}$ in human serum samples and validation results of the analyte by atomic absorption spectrometry (AAS) method compared with the presented method. $(n=3)$.

\begin{tabular}{ccccccc}
\hline $\begin{array}{c}\text { Serum } \\
\text { sample }\end{array}$ & $\begin{array}{c}\text { Added } \\
\mathrm{Fe}^{3+} \\
\left(\mu \mathrm{M} \mathrm{L}^{-1}\right)\end{array}$ & $\begin{array}{c}\text { Found Fe } \\
\left(\mu \mathrm{M} \mathrm{L}^{-1}\right)\end{array}$ & $\begin{array}{c}\text { Recovery } \\
(\%)\end{array}$ & $\begin{array}{c}\text { Found Fe }{ }^{3+} \text { by AAS } \\
\left(\mu \mathrm{M} \mathrm{L}^{-1}\right)\end{array}$ & $\begin{array}{c}\text { Recovery by } \\
\text { AAS }(\%)\end{array}$ & $\begin{array}{c}\text { T- } \\
\text { test }^{\text {a }}\end{array}$ \\
\hline $1^{\mathrm{b}}$ & - & $65.53 \pm 1.65$ & - & $65.12 \pm 1.44$ & - & 0.38 \\
& 50 & $117.43 \pm 1.73$ & 101.64 & $115.24 \pm 1.86$ & 100.11 & 0.57 \\
& 100 & $169.94 \pm 2.42$ & 102.66 & $163.53 \pm 2.24$ & 99.04 & 0.62 \\
& 150 & $220.58 \pm 3.25$ & 102.34 & $212.47 \pm 3.64$ & 98.77 & 0.51 \\
\hline $2^{\mathrm{b}}$ & - & $23.43 \pm 0.84$ & - & $23.97 \pm 0.78$ & - & 0.64 \\
$3^{\mathrm{b}}$ & - & $15.83 \pm 0.48$ & - & $16.31 \pm 0.51$ & - & 0.83 \\
$4^{\mathrm{b}}$ & - & $49.58 \pm 1.25$ & - & $48.66 \pm 1.13$ & - & 0.46 \\
$5^{\mathrm{b}}$ & - & $70.43 \pm 1.57$ & - & $72.66 \pm 1.21$ & - & 0.77 \\
$6^{\mathrm{b}}$ & - & $32.85 \pm 1.07$ & - & $31.62 \pm 0.99$ & - & 0.72 \\
$7^{\mathrm{b}}$ & - & $45.74 \pm 1.27$ & - & $46.64 \pm 1.08$ & - & 0.59 \\
\hline
\end{tabular}

${ }^{\mathrm{a}} \mathrm{T}$-Critical $=3.72$ for $\mathrm{n}=3$ and $\mathrm{P}=0.05$

${ }^{\mathrm{b}}$ Obtained from Qingdao Central Hospital 


\section{Supporting Information:}

\section{Subsequent monitoring of ferric ion and ascorbic acid using graphdiyne quantum dots-based optical sensors}

Qiang Bai ${ }^{\mathrm{a}, \mathrm{c}}$, Chaoyang Zhang ${ }^{\mathrm{b}}$, Long $\mathrm{Li}^{\mathrm{b}}$, Zhiling Zhu ${ }^{\mathrm{a}}$, Lina Wang ${ }^{\mathrm{b}, *}$, Fuyi Jiang ${ }^{\mathrm{c}}$, Manhong Liu ${ }^{\mathrm{a}}$, Zhaobo Wang ${ }^{\mathrm{a}}$, William W. Yu ${ }^{\mathrm{a}, \mathrm{d}}$, Fanglin Du ${ }^{\mathrm{a}, *}$, Zhugen Yang ${ }^{\mathrm{e}, *}$, Ning Sui ${ }^{\mathrm{a}, *}$

${ }^{a}$ College of Materials Science and Engineering, Qingdao University of Science and Technology, Qingdao 266042, China

${ }^{b}$ College of Environment and Safety Engineering, Qingdao University of Science and Technology, Qingdao, 266042, China.

${ }^{c}$ School of Environment and Material Engineering, Yantai University, Yantai, 264005, Shandong, China

${ }^{d}$ Department of Chemistry and Physics, Louisiana State University Shreveport, LA 71115, USA

${ }^{e}$ Cranfield Water Science Institute, Cranfield University, Milton Keynes, MK43 OAL, United Kingdom

* Corresponding authors: suining@qust.edu.cn (N. Sui), lnwang2006@163.com (L.N. Wang), dufanglin@qust.edu.cn (F.L. Du), zhugen.yang@ cranfield.ac.uk (Dr Z. Yang) 


\section{Contents}

1. Quantum yields (QYs) measurements.

Page S3

2. Optimization of the testing conditions.

Page S3

3. Fig. S1. AFM image of naked substrate.

Page S4

4. Fig. S2. Zeta potential of GDYO-QDs solution.

Page S4

5. Fig. S3. XPS spectra of GDY, GDYO and GDYO-QDs

Page S5

6. Fig. S4. FT-IR spectra of GDY, GDYO and GDY-QDs.

Page S5

7. Fig. S5. The O1s spectra of GDY, GDYO and GDYO-QDs.

Page S6

8. Fig. S6. UV-vis absorption spectra of GDYO.

Page S6

9. Fig. S7. The fluorescence stability of GDYO-QDs within 14 days.

Page S7

10. Fig. S8. Fluorescence spectra of different batches of GDYO-QDs.

Page S7

11. Fig. S9. Fluorescence spectra of GDYO-QDs under different $\mathrm{pH}$.

Page S8

12. Fig. S10. Optimization of $\mathrm{pH}$.

Page S8

13. Fig. S11. Optimization of reaction time (quenching by $\mathrm{Fe}^{3+}$ )

Page S9

14. Fig. S12. Optimization of $\mathrm{Fe}^{3+}$ concentration

Page S9

15. Fig. S13. Influence of AA on the fluorescence of GDYO-QDs.

Page S10

16. Fig. S14. Optimization of reaction time (recovery by AA).

Page S10

17. Fig. S15. Fluorescence recovery study.

Page S11

18. Fig. S16. Selective response towards different metal ions.

Page S11

19. Fig. S17. Interference study of GDYO-QDs sensor.

Page S12

20. Fig. S18. Fluorescence response towards $\mathrm{Ca}^{2+}, \mathrm{Mg}^{2+}, \mathrm{Fe}^{3+}$.

Page S12

21. Table S1. Elemental analysis by XPS.

Page S13

22. Table S2. Comparison of different sensors.

Page S14

23. Table S3. IFE of $\mathrm{Fe}^{3+}$ on the fluorescence of GDYO-QDs.

24. Table S4. Recoveries of AA in fetal bovine serum samples.

Page S15

Page S15

25. Reference

Page S16 


\section{Quantum yields (QYs) measurements.}

QYs of the GDYO-QDs was determined by using quinine sulfate $\left(Q Y_{R}=0.560\right.$ in water) as the standard sample and were calculated according to the following equation:

$$
\mathrm{Q} Y_{X}=Q Y_{R} \frac{I_{X}}{I_{R}} \frac{A_{R}}{A_{X}} \frac{\eta_{X}^{2}}{\eta_{R}^{2}}
$$

where QY is the quantum yield, the subscript "R" refers to the known QY standard of quinine sulfate and " $\mathrm{X}$ " means number of samples, $\mathrm{I}$ is the measured integrated emission intensity, $\mathrm{A}$ is the ultraviolet absorbance and $\eta$ is the refractive index.

\section{Optimization of the testing conditions.}

A fluorescence sensor based GDYO-QDs were established for $\mathrm{Fe}^{3+}$ and AA detection. The experimental conditions including the $\mathrm{pH}$ value of the assay and the reaction time were investigated and optimized. We used B-R buffer as a medium to detect fluorescence spectra of GDYO-QDs under different $\mathrm{pH}$ value from 2.0 to 10.0 (Figure S6a, b). The fluorescence intensity of GDYO-QDs reached the optimum at $\mathrm{pH}=6.0$. After the addition $\mathrm{Fe}^{3+}$, sharp decreases of the fluorescence intensity were observed at each $\mathrm{pH}$ value (Figure S7). The largest change of the fluorescence intensity occurred at $\mathrm{pH}=6.0$ in the absence and presence of $\mathrm{Fe}^{3+}$, which indicates that the best quenching effect occurs when $\mathrm{pH}=6.0$. Figure $\mathrm{S} 8$ a shows the time-dependent fluorescence spectra of GDYO-QDs $\left(0.1 \mathrm{mg} \mathrm{mL}^{-1}\right)$ mixed with $200 \mu \mathrm{mol} \mathrm{L}^{-1}$ of $\mathrm{Fe}^{3+}$. The fluorescence intensity of GDYO-QDs decreased with the increase of reaction time and became insignificantly after 20 minutes (Figure S8b). Therefore, the optimum experimental conditions are $\mathrm{pH}=6.0$ and reaction time of $20 \mathrm{~min}$. As shown in Figure $\mathrm{S} 9 \mathrm{a}$, the quenching efficiency of GDYO-QDs by different concentrations of $\mathrm{Fe}^{3+}$ were about the same. On this premise, AA investigated the recovery under different concentrations of $\mathrm{Fe}^{3+}$, and the recovery was the best when $\mathrm{Fe}^{3+}$ was $200 \mu \mathrm{mol} \mathrm{L}{ }^{-1}$ (Figure S9b). 


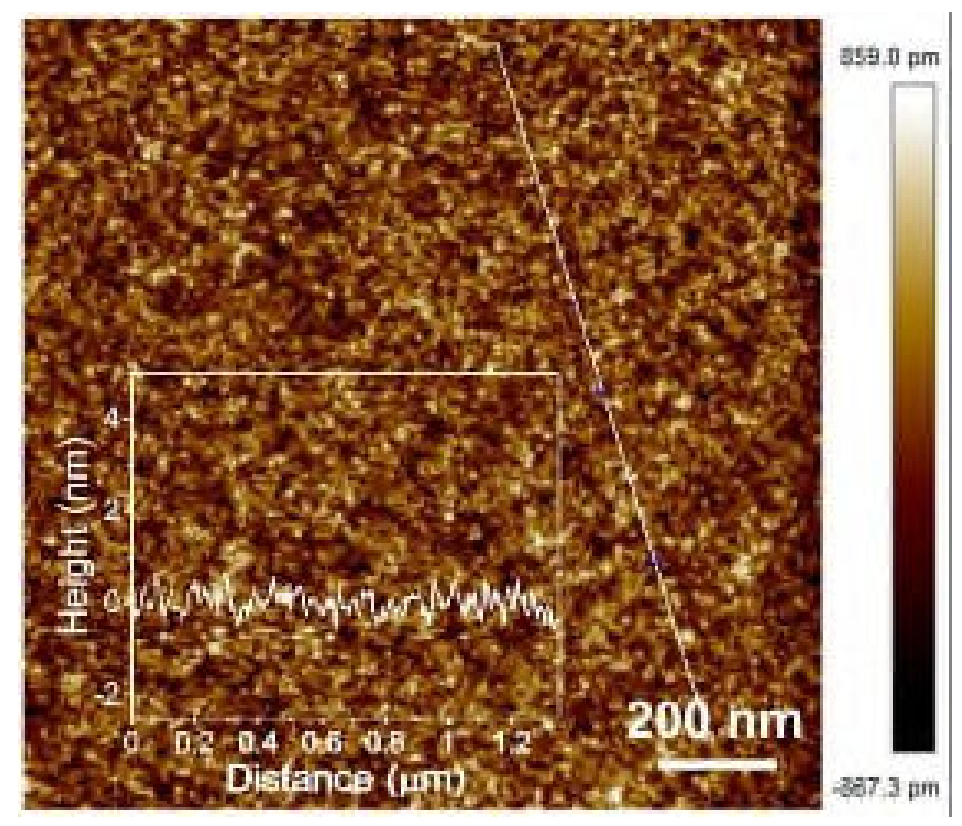

Fig. S1. AFM image of naked substrate.

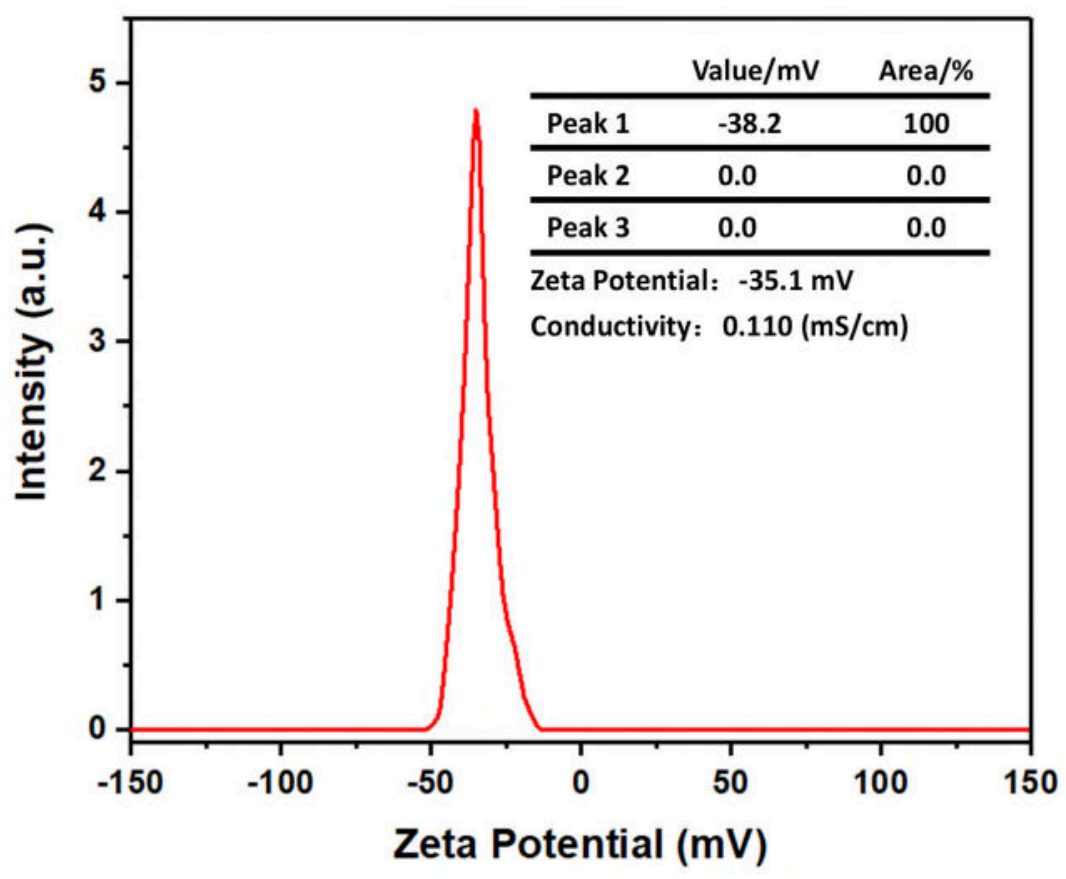

Fig. S2. Zeta potential of GDYO-QDs solution. 

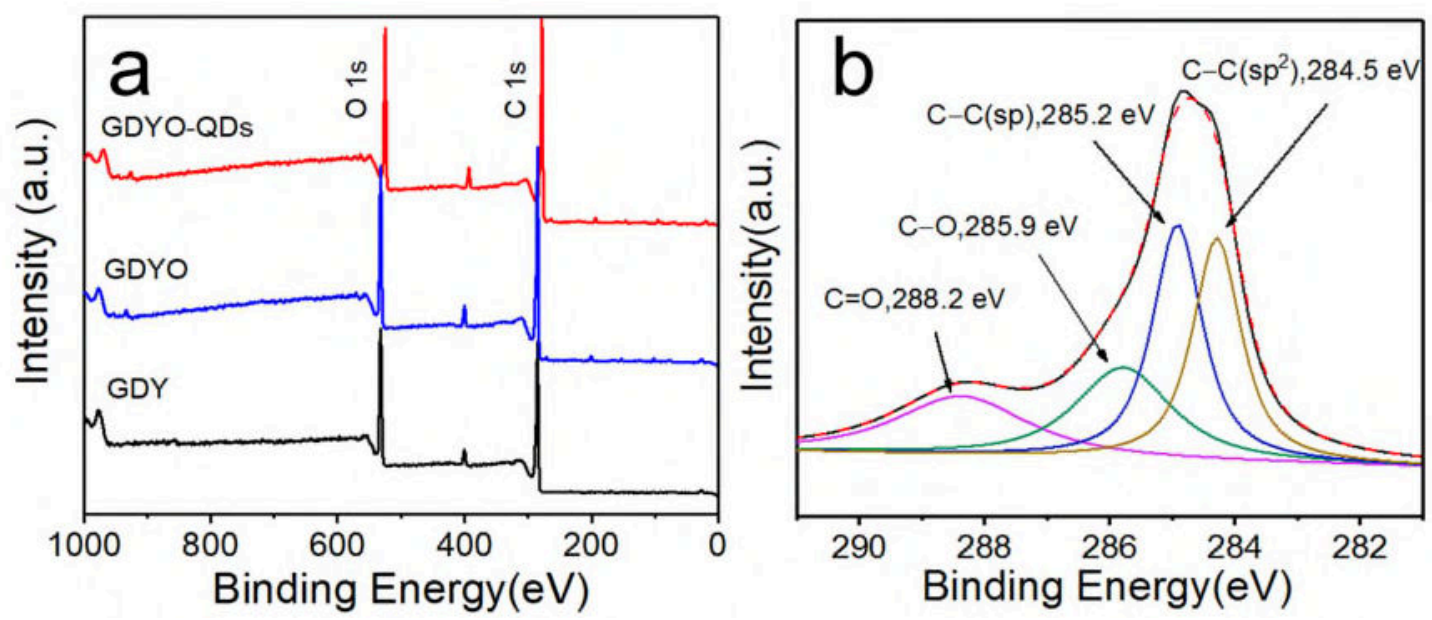

Figure S3. (a) XPS spectra of GDY, GDYO and GDYO-QDs. (b) Highresolution C1s spectra of GDYO

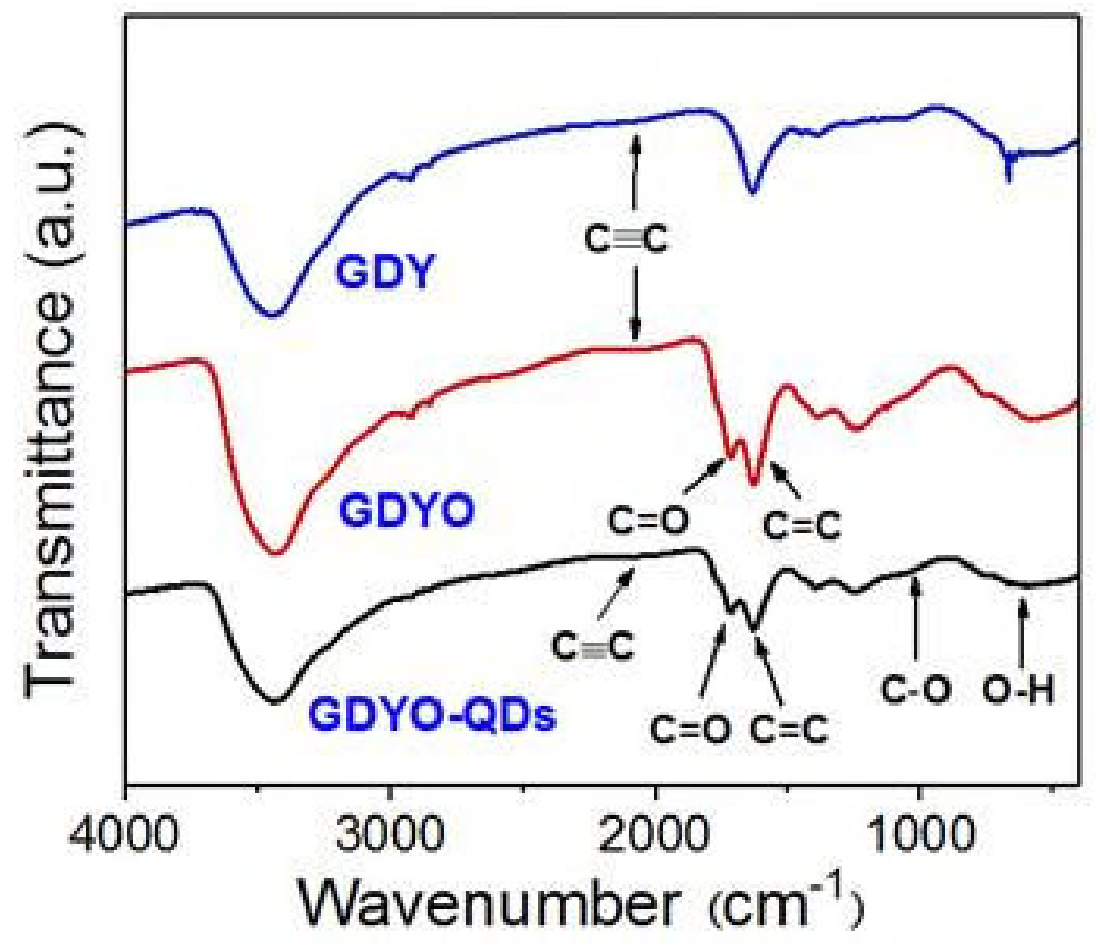

Fig. S4. FT-IR spectra of GDY, GDYO and GDY-QDs. 

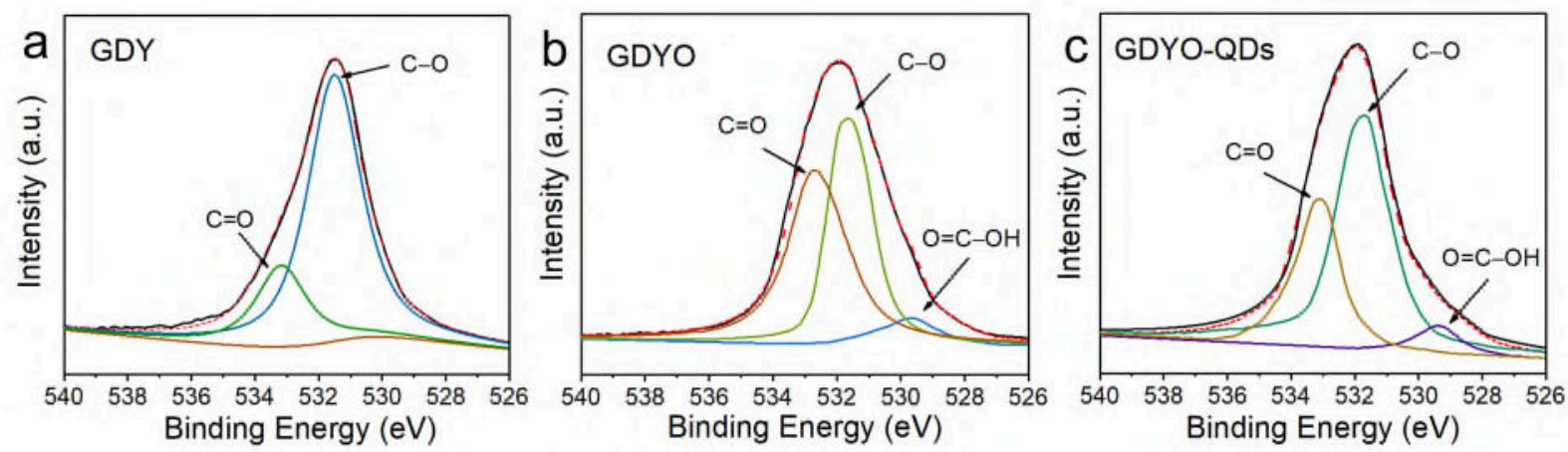

Fig. S5. The O1s spectra of (a) GDY, (b) GDYO and (c) GDYO-QDs.

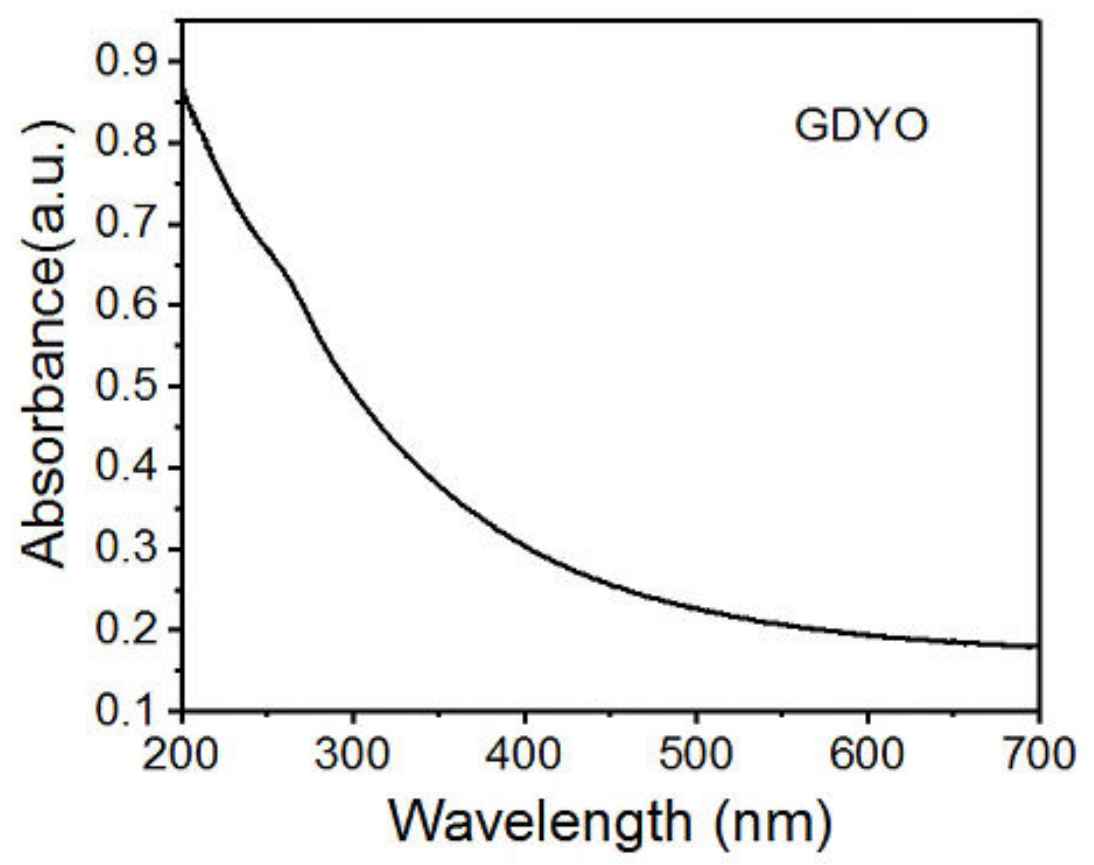

Fig. S6. UV-vis absorption spectra of GDYO. 


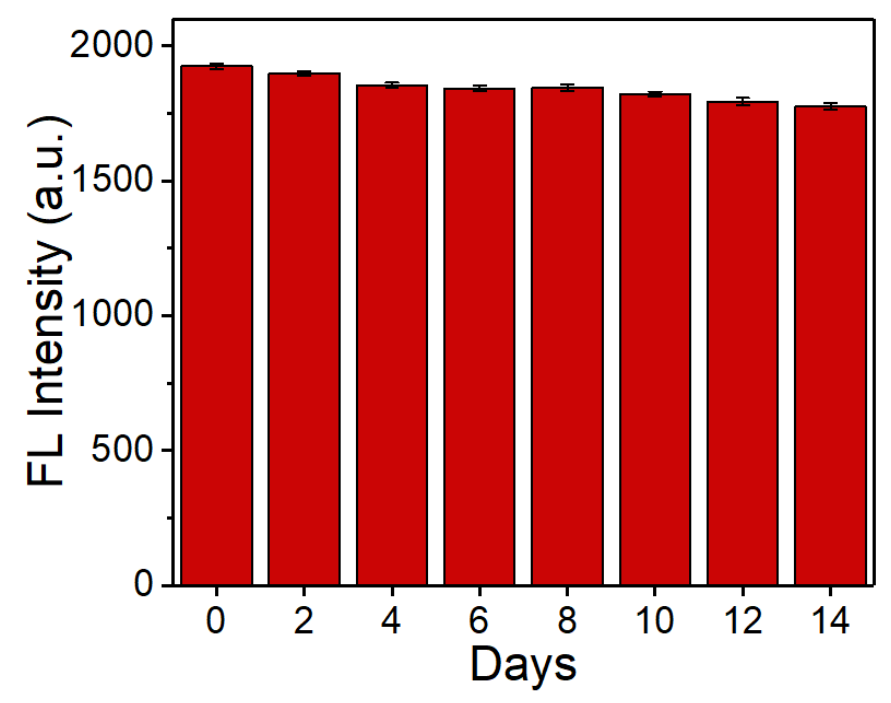

Fig. S7. The fluorescence stability of GDYO-QDs within 14 days.
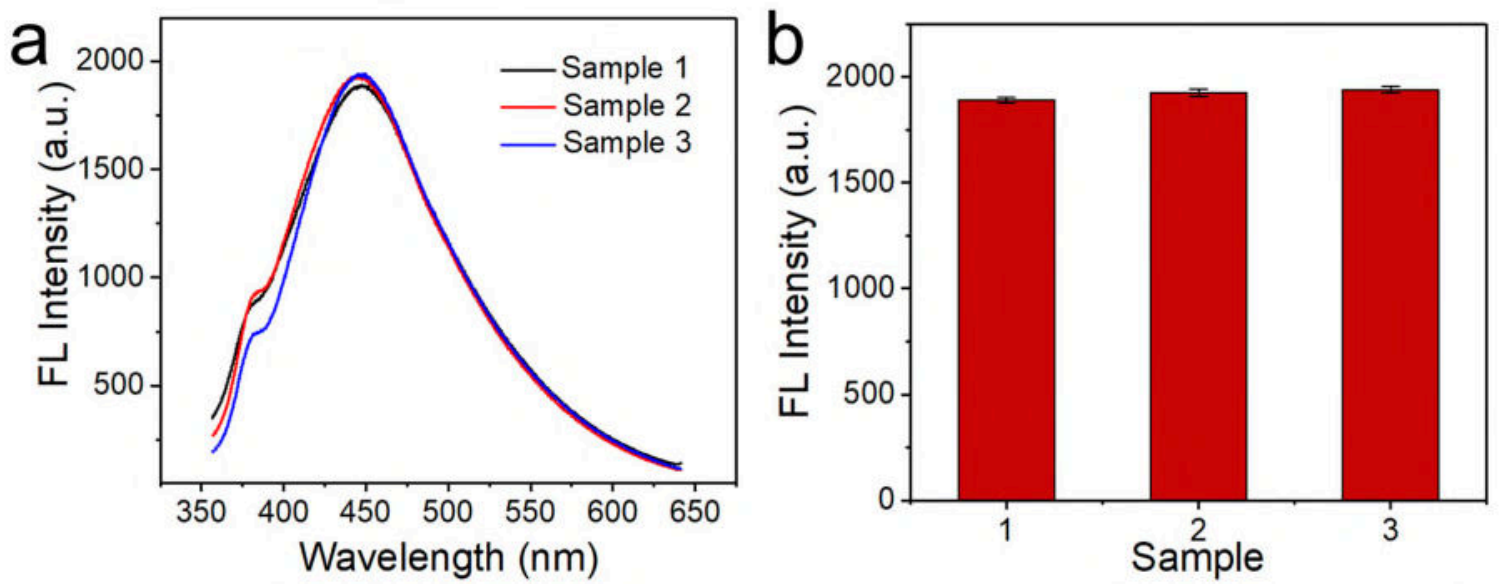

Fig. S8. (a) Fluorescence spectra of different batches of GDYO-QDs. (b) Histogram of fluorescence intensity comparison. 

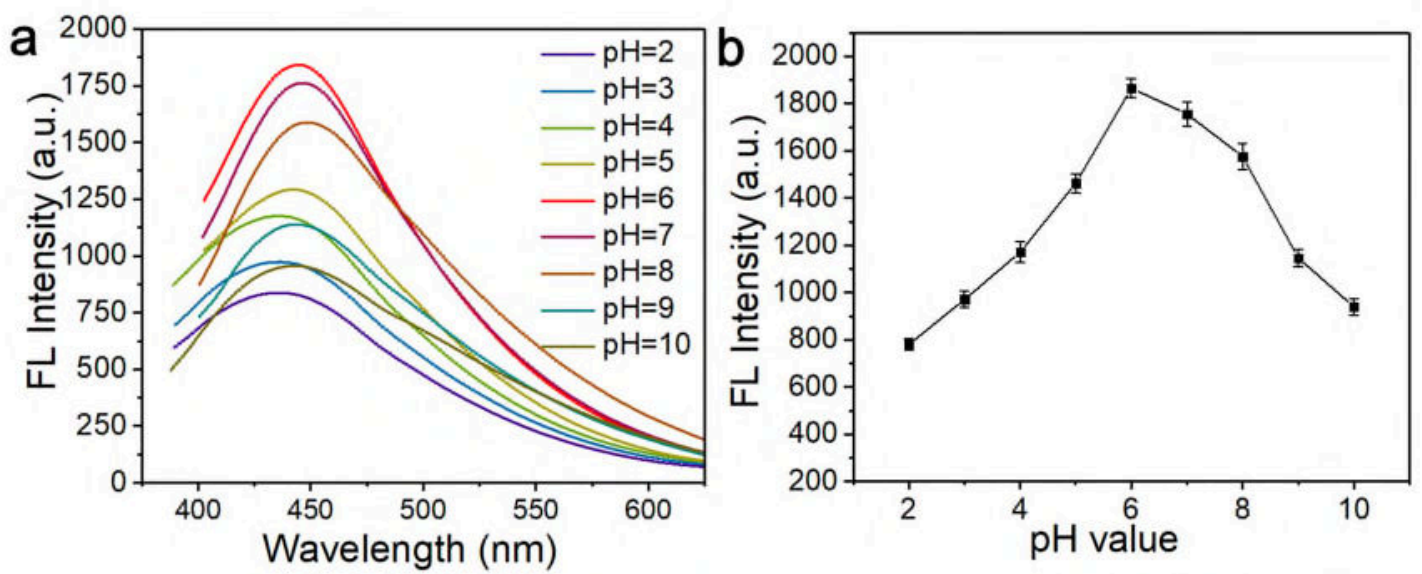

Fig. S9 (a) Fluorescence spectra of GDYO-QDs under different pH.

(b) Effect of $\mathrm{pH}$ on the GDYO-QDs

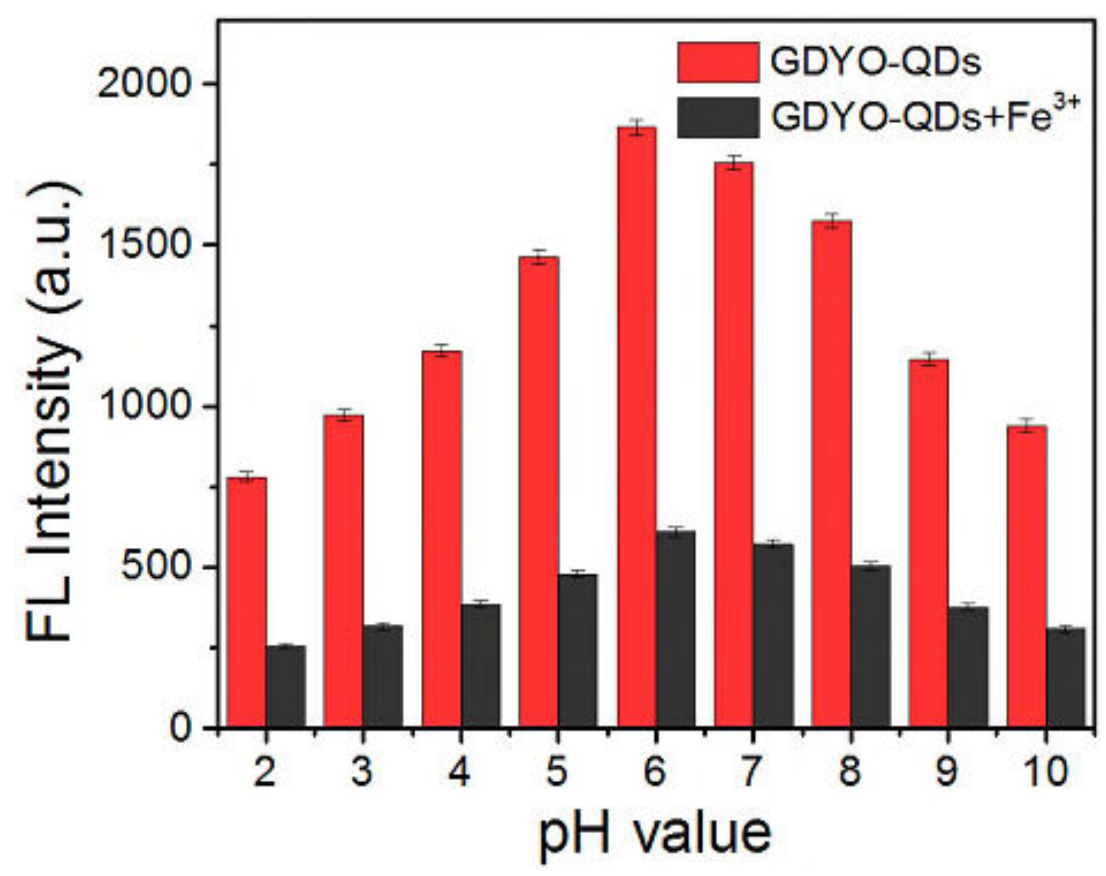

Fig. S10. The fluorescence response of GDYO-QDs without and with 50 $\mu \mathrm{mol} \mathrm{L} \mathrm{L}^{-1} \mathrm{Fe}^{3+}$ at different $\mathrm{pH}$ values. 

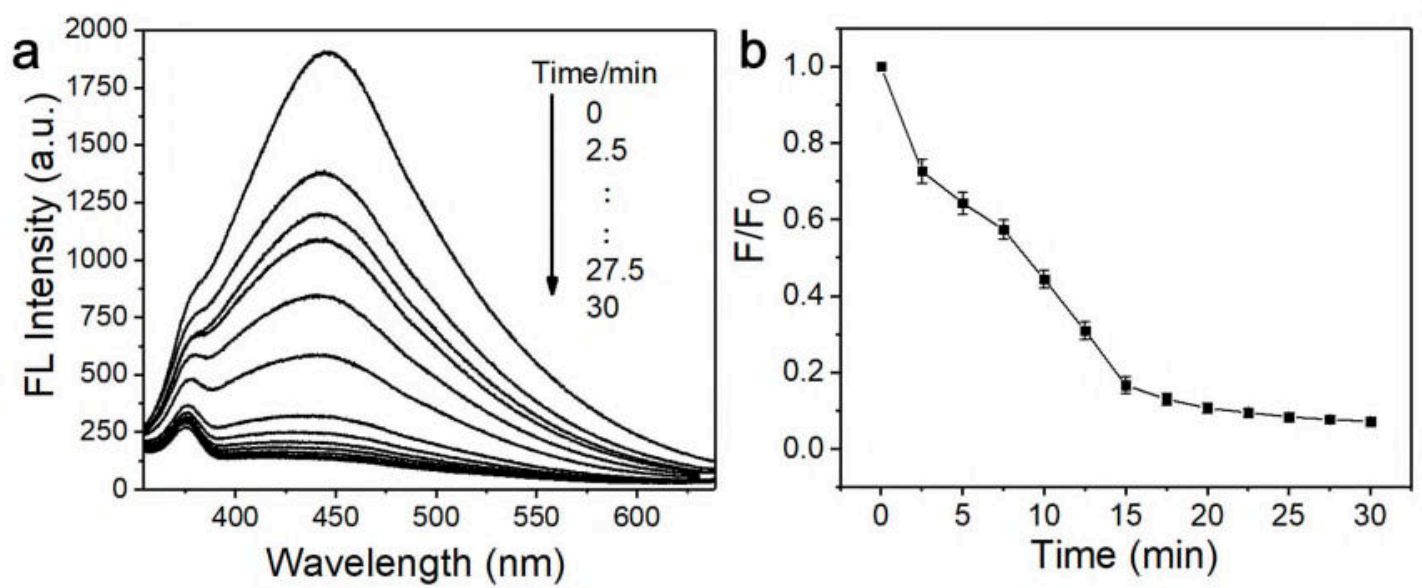

Fig. S11. (a) Fluorescence quenching of GDYO-QDs by $200 \mu \mathrm{mol} \mathrm{L}{ }^{-1}$ $\mathrm{Fe}^{3+}$ in B-R buffer $(\mathrm{pH}=6)$ as a function of time $\left(\lambda_{\mathrm{ex}}=331 \mathrm{~nm}\right)$. (b) The change of $\mathrm{F}_{0} / \mathrm{F}$ with the reaction time.
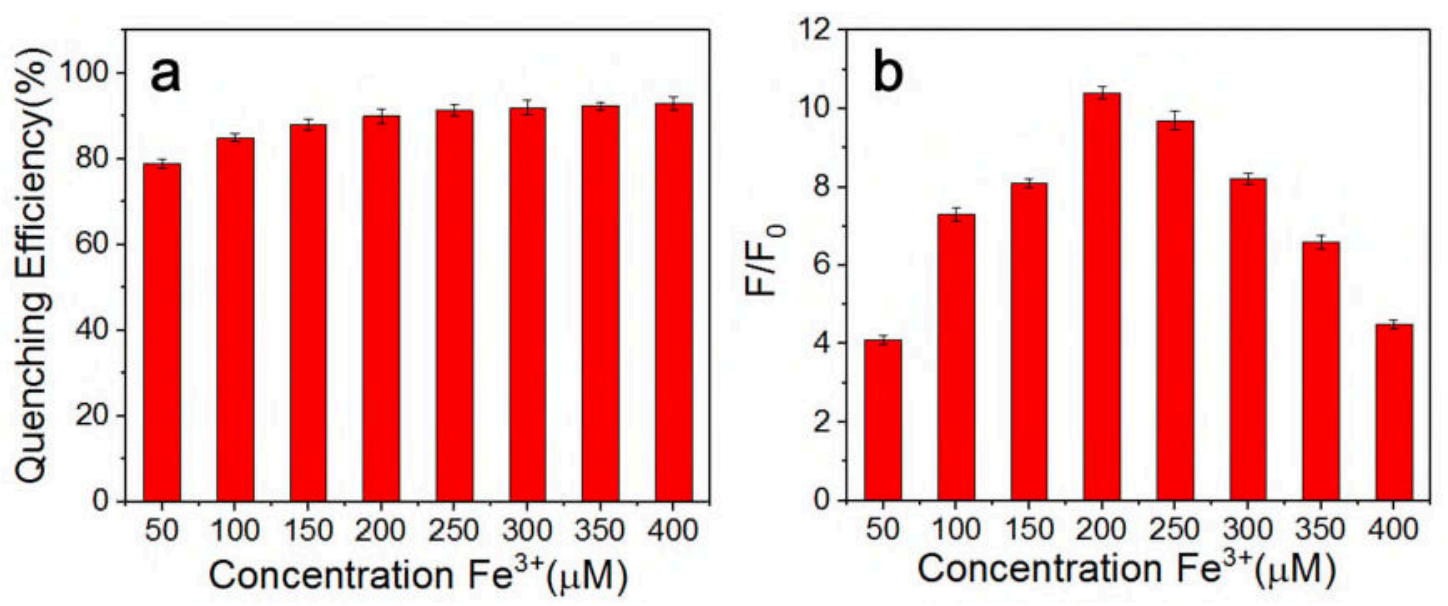

Fig. S12. (a) The quenching efficiency of GDYO-QDs to various concentrations of $\mathrm{Fe}^{3+}$. (b) The sensitivity of AA $\left(500 \mu \mathrm{mol} \mathrm{L} \mathrm{L}^{-1}\right)$ response to different concentrations of $\mathrm{Fe}^{3+} .\left(\mathrm{F}_{0}\right.$ and $\mathrm{F}$ are the fluorescence intensities of GDYO-QDs $/ \mathrm{Fe}^{3+}$ in the absence and presence of AA, respectively) 


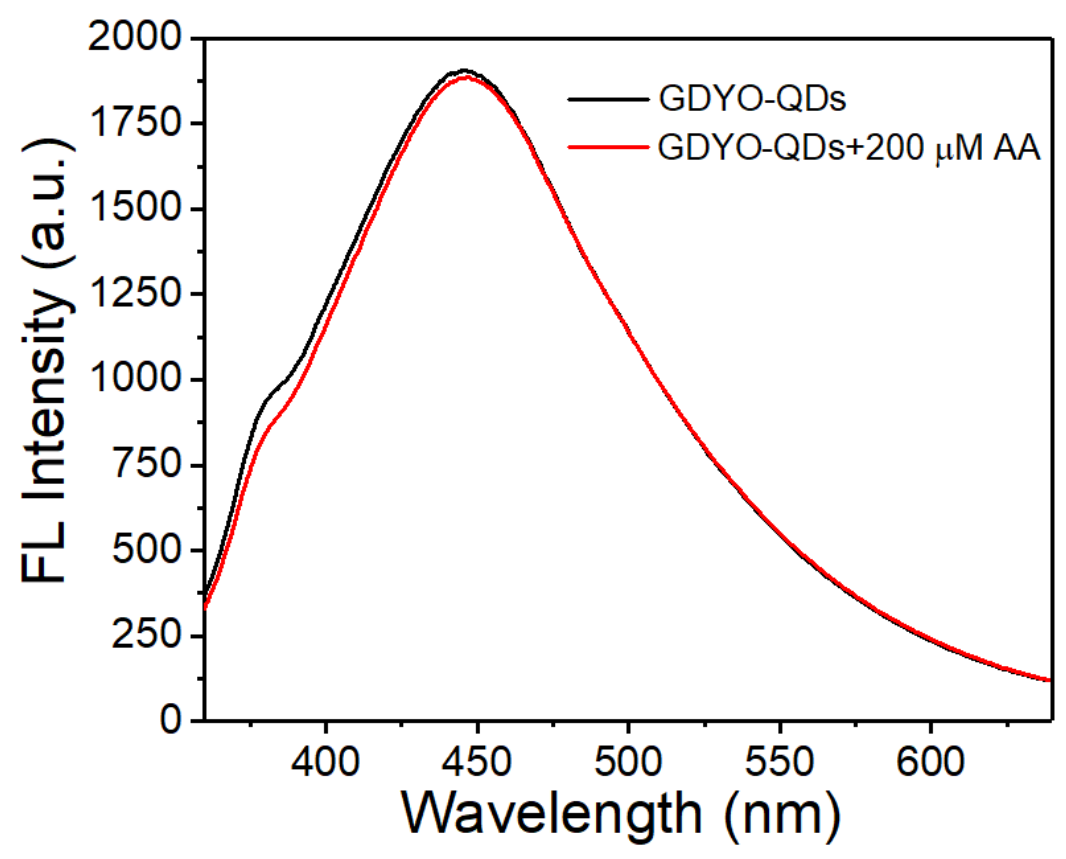

Fig. S13. Fluorescence spectra of GDYO-QDs and GDYO-QDs with AA.

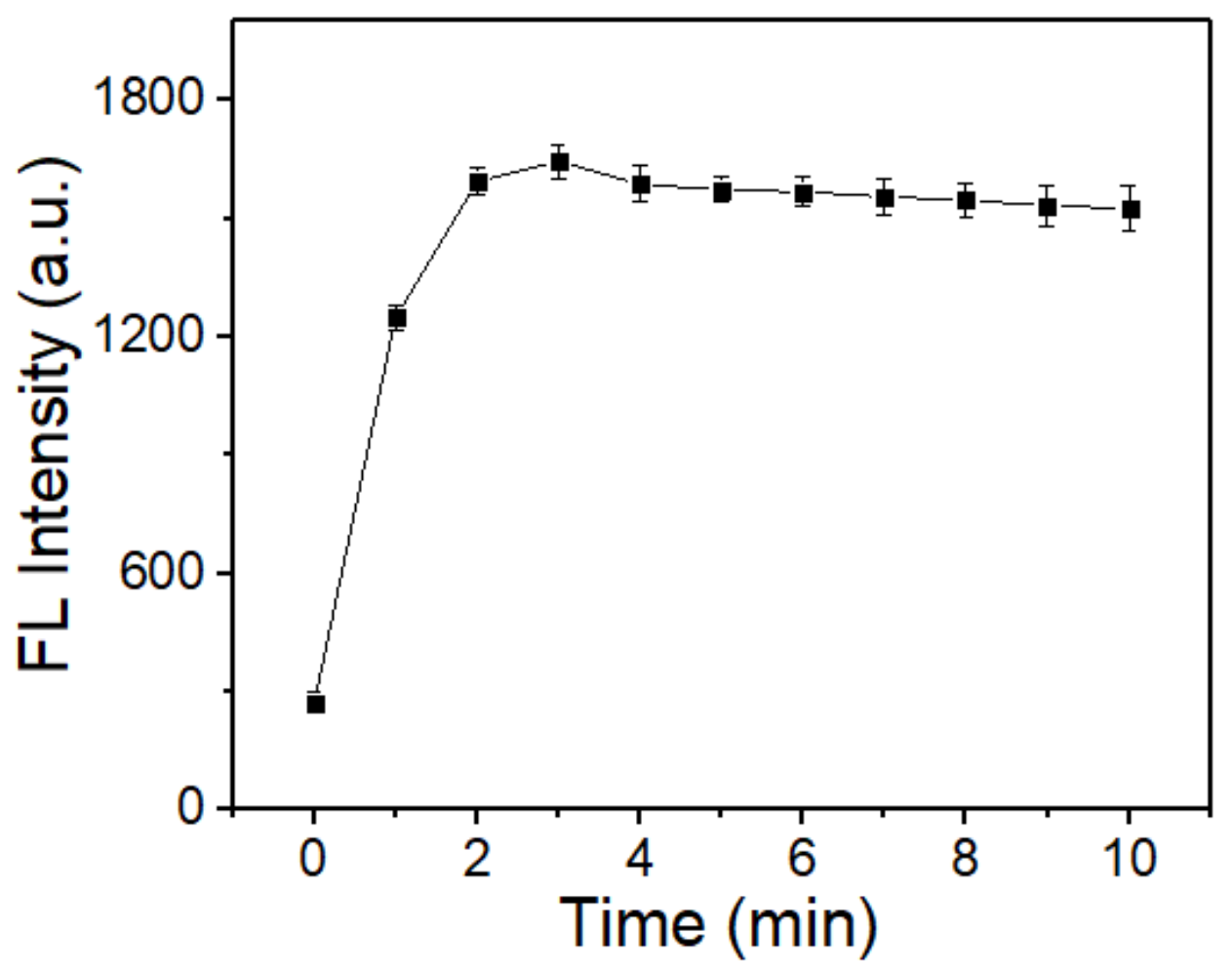

Fig. S14. Fluorescence intensity of GDYO-QDs / $\mathrm{Fe}^{3+}$ after reaction with AA $\left(400 \mu \mathrm{mol} \mathrm{L}{ }^{-1}\right)$ for different times. 


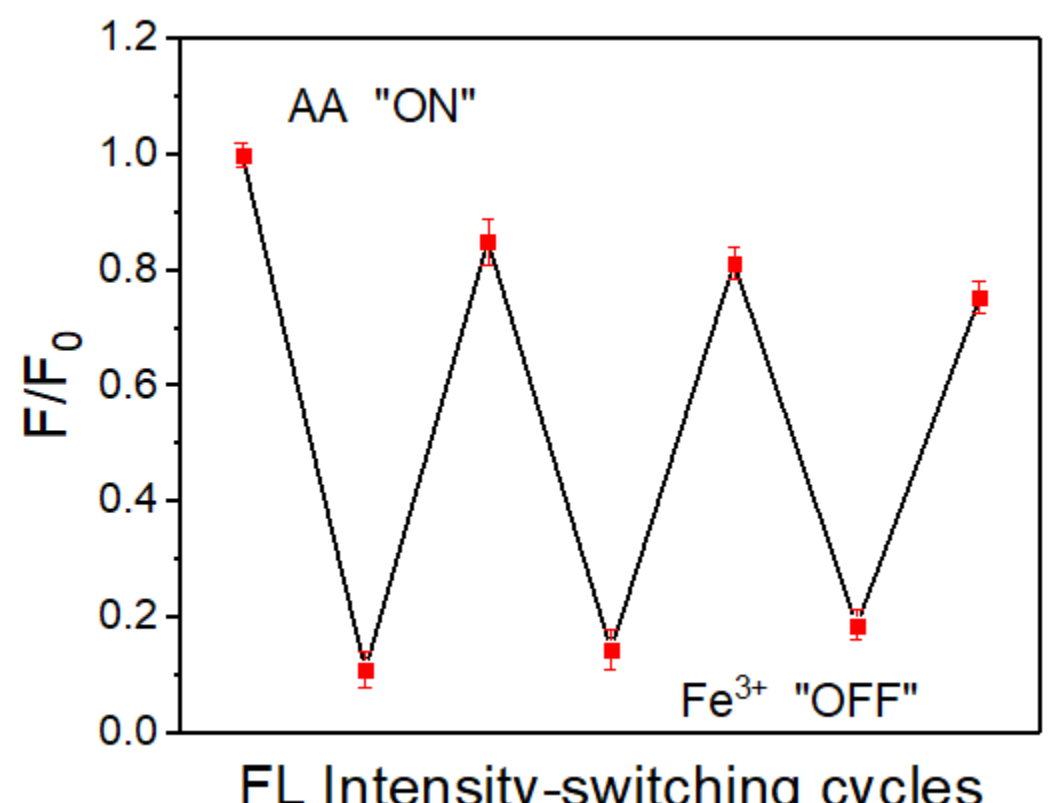

Fig. S15. Reversible of GDYO-QDs upon alternate addition of $\mathrm{Fe}^{3+}$ and AA.

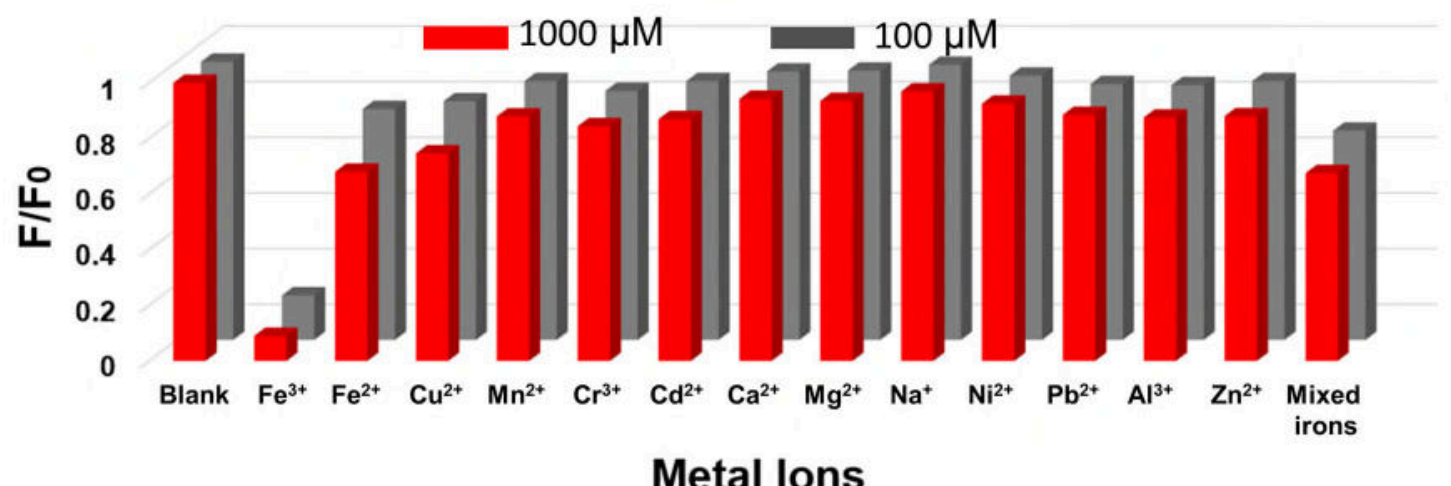

Fig. S16. Selective response of aqueous GDYO-QDs towards different metal ions $\left(\lambda_{\mathrm{ex}}=331 \mathrm{~nm}\right) . \mathrm{F}_{0}$ and $\mathrm{F}$ are the fluorescence intensities of GDYO-QDs at $446 \mathrm{~nm}$ in the absence and presence of metal ions, respectively. 


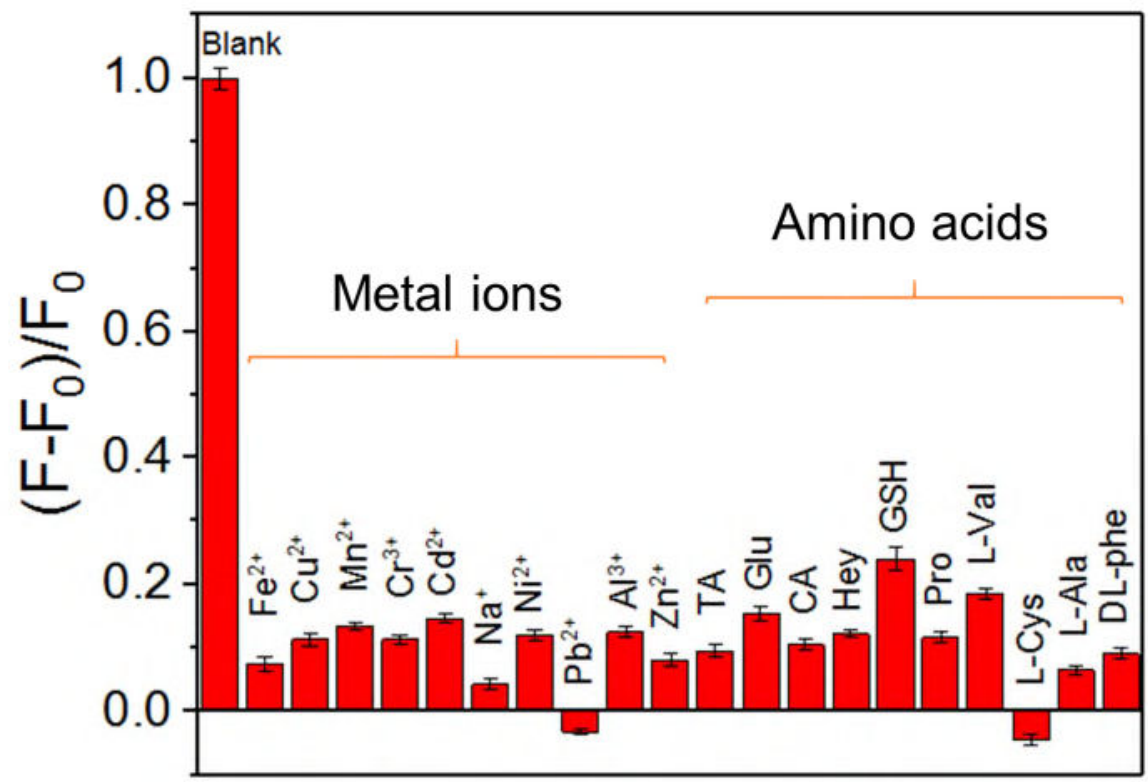

\section{Interfering Substances}

Fig. S17. An interference study of GDYO-QDs sensor for $\mathrm{Fe}^{3+}(200 \mu \mathrm{mol}$

$\left.\mathrm{L}^{-1}\right)$ and AA (400 $\left.\mu \mathrm{mol} \mathrm{L}^{-1}\right)$ premixed with other interfering substances $(400 \mu \mathrm{mol} \mathrm{L}-1)$.

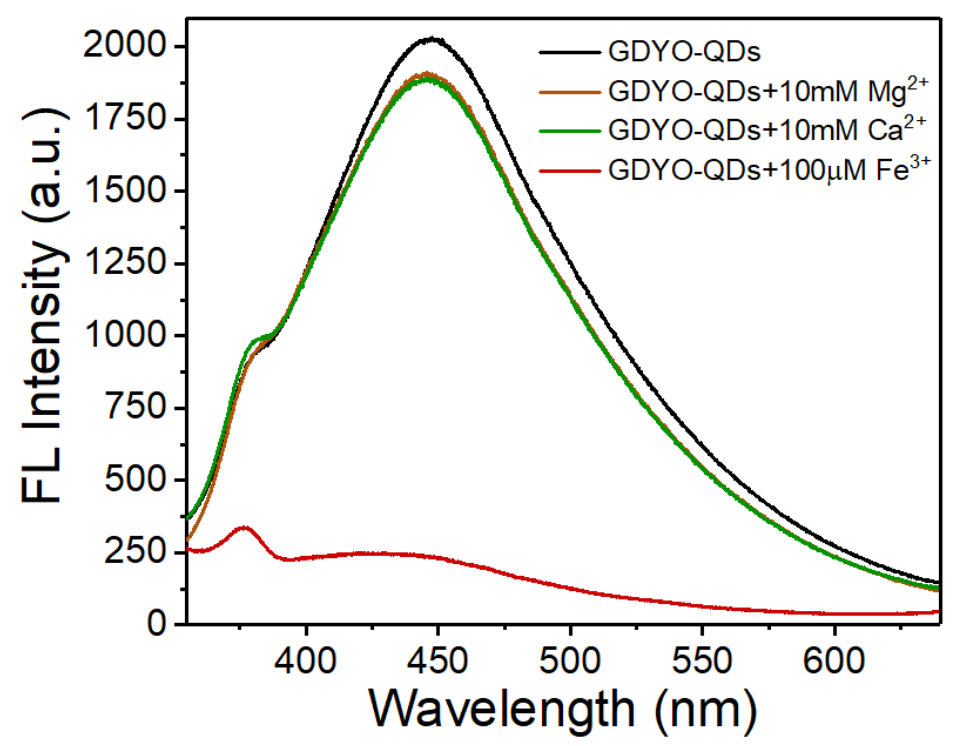

Fig. S18. Fluorescence response of GDYO-QDs in the presence of 10 mmol L ${ }^{-1}$ of $\mathrm{Mg}^{2+}, 10 \mathrm{mM}$ of $\mathrm{Ca}^{2+}$ and $100 \mu \mathrm{M}$ of $\mathrm{Fe}^{3+}$. 
Table S1. Elemental analysis of the GDY, GDYO and GDYO-QDs by XPS

\begin{tabular}{ccc}
\hline Element & C & O \\
\hline GDY(\%) & 78.78 & 21.22 \\
GDYO (\%) & 73.26 & 26.74 \\
GDYO-QDs(\%) & 68.43 & 31.57 \\
\hline
\end{tabular}


Table S2. Performance of the new sensor (GDYO-QDs) compared with other reported fluorescence sensors for analysis of $\mathrm{Fe}^{3+}$ and AA.

\begin{tabular}{|c|c|c|c|c|c|c|}
\hline \multirow[b]{2}{*}{ Probe } & \multicolumn{3}{|c|}{$\mathbf{F e}^{3+}$} & \multicolumn{2}{|c|}{$\mathbf{A A}$} & \multirow[b]{2}{*}{ Ref. } \\
\hline & $\begin{array}{c}\text { Liner } \\
\text { Range/ } \mu \mathrm{M}\end{array}$ & $\begin{array}{l}\text { LOD } \\
(\mu \mathrm{M})\end{array}$ & $\begin{array}{l}\text { Quenching } \\
\text { Mechanism }\end{array}$ & 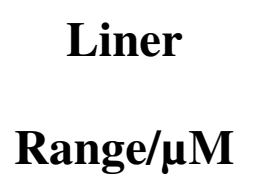 & $\begin{array}{l}\text { LOD } \\
(\mu \mathrm{M})\end{array}$ & \\
\hline $\begin{array}{c}\text { MIL-53(Fe)- } \\
(\mathrm{OH})_{2}\end{array}$ & $5 \sim 200$ & 1.7 & PET & - & - & {$[1]$} \\
\hline b-CDs & $1 \sim 60$ & 0.28 & PET & - & - & {$[2]$} \\
\hline ZnMOF-74 & $0.1 \sim 100$ & 0.04 & PET & - & - & {$[3]$} \\
\hline CNQDs & $2 \sim 200$ & 1.0 & PET & - & - & {$[4]$} \\
\hline MPS & $0 \sim 100$ & 1.54 & SQ a & - & - & {$[5]$} \\
\hline g-CN QDs & $0.2 \sim 60$ & 0.023 & IFE & - & - & {$[6]$} \\
\hline MIL- 53(Al) & $3 \sim 200$ & 0.9 & PET & - & - & [7] \\
\hline $\mathrm{Bi}_{2} \mathrm{~S}_{3}-\mathrm{TiO}_{2}$ & $30 \sim 5000$ & 0.1173 & PET & - & - & [8] \\
\hline $\begin{array}{c}\text { N,S-doped } \\
\text { CDs }\end{array}$ & - & - & PET & $10 \sim 200$ & 4.69 & [9] \\
\hline GDQs & - & - & FRET & $1.0 \sim 95$ & 0.2 & {$[10]$} \\
\hline GSH-Ag & - & - & - & $4 \sim 300$ & 0.1 & {$[11]$} \\
\hline $\mathrm{g}-\mathrm{C}_{3} \mathrm{~N}_{4} \mathrm{NNs}$ & $0.5 \sim 30$ & 0.18 & IFE, PET & $0.2 \sim 112.5$ & 0.086 & [12] \\
\hline GDYO-QDs & $0.25 \sim 200$ & 0.095 & $\begin{array}{c}\text { SQ, IFE, } \\
\text { PET }\end{array}$ & $10 \sim 500$ & 2.5 & $\begin{array}{l}\text { This } \\
\text { work }\end{array}$ \\
\hline
\end{tabular}


Table S3. IFE of $\mathrm{Fe}^{3+}$ on the fluorescence of GDYO-QDs

\begin{tabular}{cccccccc}
\hline $\mathbf{F e}^{3+} / \boldsymbol{\mu M}$ & $\mathbf{A}_{\text {ex }}$ & $\mathbf{A}_{\text {em }}$ & $\mathbf{C F}$ & $\mathbf{F}_{\text {obsd }}$ & $\mathbf{F}_{\text {cor }}$ & $\mathbf{Q}_{\text {obsd }}$ & $\mathbf{Q}_{\text {cor }}$ \\
\hline $\mathbf{0}$ & 0.175 & 0.139 & 1.1064 & 1867 & 2613.4 & 0 & 0 \\
$\mathbf{2 0}$ & 0.314 & 0.236 & 1.7005 & 906 & 1540.6 & 0.5417 & 0.4105 \\
$\mathbf{4 0}$ & 0.538 & 0.341 & 2.4607 & 541 & 1331.2 & 0.7102 & 0.4906 \\
$\mathbf{6 0}$ & 0.668 & 0.446 & 3.0989 & 401 & 1242.7 & 0.7852 & 0.5245 \\
$\mathbf{8 0}$ & 0.768 & 0.553 & 3.7373 & 318 & 1188.5 & 0.8297 & 0.5452 \\
$\mathbf{1 0 0}$ & 0.870 & 0.642 & 4.4296 & 252 & 1116.3 & 0.8650 & 0.5729 \\
$\mathbf{1 2 0}$ & 0.918 & 0.731 & 5.0028 & 226 & 1085.6 & 0.8789 & 0.5847 \\
$\mathbf{1 4 0}$ & 0.976 & 0.820 & 5.7399 & 197 & 1060.3 & 0.8945 & 0.5943 \\
$\mathbf{1 6 0}$ & 1.0288 & 0.903 & 5.9969 & 175 & 1049.5 & 0.9043 & 0.5984 \\
\hline
\end{tabular}

Table S4. Recoveries of AA in human serum samples $(n=3)$.

\begin{tabular}{lccll}
\hline Sample & $\begin{array}{c}\text { Added } \\
\left(\boldsymbol{\mu} \mathbf{M ~ L}^{-\mathbf{1}}\right)\end{array}$ & $\begin{array}{c}\text { Found } \\
\left(\boldsymbol{\mu} \mathbf{M ~ L}^{-\mathbf{1}}\right)\end{array}$ & $\begin{array}{l}\text { Recovery } \\
(\boldsymbol{\%})\end{array}$ & $\begin{array}{l}\text { RSD } \\
(\boldsymbol{\%})\end{array}$ \\
\hline $\mathbf{1}$ & 0 & 0 & - & - \\
\hline $\mathbf{2}$ & 50 & $48.87 \pm 0.70$ & 97.74 & 1.28 \\
\hline $\mathbf{3}$ & 200 & $204.54 \pm 4.65$ & 102.27 & 1.97 \\
\hline $\mathbf{4}$ & 400 & $394.28 \pm 8.80$ & 98.57 & 2.12 \\
\hline
\end{tabular}




\section{Reference}

[1] Zhao Y, Ouyang H, Feng S, Luo Y, Shi Q, Zhu C, et al. Rapid and selective detection of Fe (III) by using a smartphone-based device as a portable detector and hydroxyl functionalized metal-organic frameworks as the fluorescence probe. Anal Chim Acta 2019;1077:160-6.

[2] Xu X, Ren D, Chai Y, Cheng X, Mei J, Bao J, et al. Dual-emission carbon dotsbased fluorescent probe for ratiometric sensing of $\mathrm{Fe}(\mathrm{III})$ and pyrophosphate in biological samples. Sensors and Actuators B: Chemical 2019;298.

[3] Hou L, Song Y, Xiao Y, Wu R, Wang L. ZnMOF-74 responsive fluorescence sensing platform for detection of $\mathrm{Fe}^{3+}$. Microchemical Journal 2019;150.

[4] Li S, Li Y, Cao J, Zhu J, Fan L, Li X. Sulfur-Doped Graphene Quantum Dots as a Novel Fluorescent Probe for Highly Selective and Sensitive Detection of $\mathrm{Fe}^{3+}$. Analytical Chemistry 2014;86:10201-7.

[5] Wang X, Wang H, Feng S. A novel thiophene functionalized silicon-cored compounds: Aggregation-induced emission enhancement and aqueous fluorogenic $\mathrm{Fe}^{3+}$ probes in bovine serum albumin. Sensors and Actuators B: Chemical 2017;241:65-72. [6] Li Y, Cai J, Liu F, Yu H, Lin F, Yang H, et al. Highly crystalline graphitic carbon nitride quantum dots as a fluorescent probe for detection of Fe(III) via an innner filter effect. Microchim Acta 2018;185:134

[7] Zhang Y-L, Wang L, Zhang H-C, Liu Y, Wang H-Y, Kang Z-H, et al. Graphitic carbon quantum dots as a fluorescent sensing platform for highly efficient detection of $\mathrm{Fe}^{3+}$ ions. RSC advances 2013;3:3733-8.

[8] Syal A, Sud D. Development of highly selective novel fluorescence quenching probe based on $\mathrm{Bi}_{2} \mathrm{~S}_{3}-\mathrm{TiO}_{2}$ nanoparticles for sensing the $\mathrm{Fe}(\mathrm{III})$. Sensors and Actuators B: Chemical 2018;266:1-8.

[9] Luo, X. L.; Zhang, W. G.; Han, Y.; Chen, X. M.; Zhu, L.; Tang, W. Z.; Wang, J. L.; Yue, T. L.; Li, Z. H. N,S co-doped carbon dots based fluorescent "on-off-on" sensor for determination of ascorbic acid in common fruits. Food Chem. 2018, 258, 214-221. 
[10] Gao, Y.; Yan, X. L.; Li, M.; Gao, H.; Sun, J.; Zhu, S. Y.; Han, S.; Jia, L. N.; Zhao, X. E.; Wang, H. A “turn-on” fluorescence sensor for ascorbic acid based on graphene quantum dots via fluorescence resonance energy transfer. Anal. Methods 2018, 10, 611616.

[11] Li, N.; He, Y.; Ge, Y. L.; Song, G. W. "Turn-Off-On” Fluorescence Switching of Ascorbic Acid-Reductive Silver Nanoclusters: a Sensor for Ascorbic Acid and Arginine in Biological Fluids. J. Fluoresc. 2017, 27, 293-302.

[12] X. Guo, G. Yue, J. Huang, C. Liu, Q. Zeng, L. Wang, Label-Free Simultaneous Analysis of $\mathrm{Fe}(\mathrm{III})$ and Ascorbic Acid Using Fluorescence Switching of Ultrathin Graphitic Carbon Nitride Nanosheets, Acs Applied Materials \& Interfaces. 10 (2018) 26118-26127. 
2020-11-16

\section{Subsequent monitoring of ferric ion and} ascorbic acid using graphdiyne quantum dots-based optical sensors

\section{Bai, Qiang}

Springer

Bai Q, Zhang C, Li L, et al., (2020) Subsequent monitoring of ferric ion and ascorbic acid using graphdiyne quantum dots-based optical sensors. Microchimica Acta, Volume 187, December 2020, Article number 657

https://doi.org/10.1007/s00604-020-04624-w

Downloaded from Cranfield Library Services E-Repository 